\title{
ACTIVATED MACROPHAGES DECREASE RAT CARDIAC MYOCYTE CONTRACTILITY: IMPORTANCE OF ICAM-1 DEPENDENT ADHESION
}

By

Matthew G. Simms

B.Sc. (Honours Biology), Saint Mary's University, 1996

B.A., Saint Mary's University, 1994

A THESIS SUBMITTED IN PARTIAL FULFILMENT OF

THE REQUIREMENTS FOR THE DEGREE OF

MASTERS OF SCIENCE

IN

THE FACULTY OF GRADUATE STUDIES

DEPARTMENT OF EXPERIMENTAL MEDICINE

We accept this thesis as conforming to the required standard

THE UNIVERSITY OF BRITISH COLUMBIA

April 1998

(CMatthew Graham Simms, 1998 
In presenting this thesis in partial fulfilment of the requirements for an advanced degree at the University of British Columbia, I agree that the Library shall make it freely available for reference and study. I further agree that permission for extensive copying of this thesis for scholarly purposes may be granted by the head of my department or by his or her representatives. It is understood that copying or publication of this thesis for financial gain shall not be allowed without my written permission.

Department of SXPBRMENIAC MEDICINE

The University of British Columbia Vancouver, Canada

Date ARRIC 24,1998 


\section{ABSTRACT}

Macrophages are found in the heart as part of the inflammatory response. Our goal was to determine whether macrophages could contribute to myocardial dysfunction. Rat ventricular myocytes were isolated using a collagenase perfusion system and cultured for 24 hours. Then myocytes were co-cultured with elicited peritoneal macrophages in media alone or in media containing TNF $\alpha, \mathrm{IL}-1 \beta$, or endotoxin for 4 hours. Myocytes were electrically stimulated and fractional shortening was determined using videomicroscopy. When myocytes alone were challenged with TNF $\alpha$, or LPS, fractional shortening did not decrease. When macrophages were prevented from adhering to myocytes by well inserts, TNF $\alpha$ and LPS did not have an effect. Fractional shortening of myocytes decreased from $20.3 \pm 1.1 \%$ in unchallenged macrophage-myocyte co-cultures, without inserts, to $15.3 \pm$ $1.1 \%$ and $15.1 \pm 1.8 \%$ when challenged for 4 hours with TNF $\alpha$ or endotoxin respectively $(p<0.05)$. After 4 hours, the challenged myocytes had a mean adherence of $4.2 \pm 0.2$ macrophages compared to $2.6 \pm 0.3$ for controls $(p<0.05)$. The number of adherent macrophages was associated with the decrease in fractional shortening. ELISA showed dose dependent ICAM-1 expression on myocytes, while VCAM-1 did not induce measurable expression. Antibody to ICAM-1 reduced macrophage adherence and prevented the decrease in fractional shortening. The decrease in fractional shortening was also prevented by anti-TNF $\alpha$, desferoxamine, SOD, and L-NAME. These results suggest that activated macrophages adhere to cardiac myocytes via ICAM-1 and adherent macrophages decrease cardiac myocyte contractile function via TNF $\alpha$, oxygen free radicals, and nitric oxide.

$$
\text { ir }
$$




\section{TABLE OF CONTENTS}

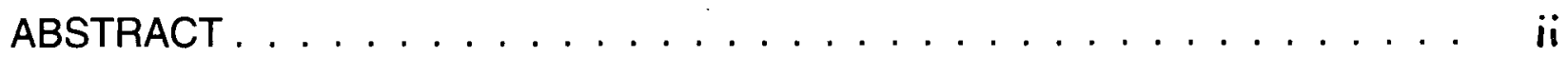

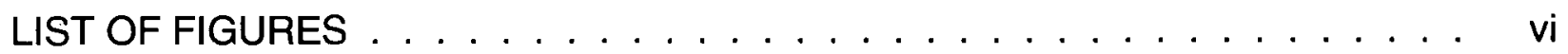

LIST OF TABLES . . . . . . . . . . . . . . . . . . . . . vii

LIST OF ABBREVIATIONS . . . . . . . . . . . . . . . . . . viii

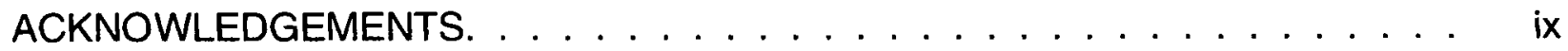

CHAPTER 1: INTRODUCTION. . . . . . . . . . . . . . . . . . 1

1.1 History of Septic Shock . . . . . . . . . . . . . . . . . . . . . 1

1.2 Statistics of the Syndrome . . . . . . . . . . . . . 3

1.3 Previous Research $\ldots \ldots \ldots \ldots$

CHAPTER 2: METHODS . . . . . . . . . . . . . . . . . . . . . . 10

2.1 Isolation of Rat Ventricular Myocytes . . . . . . . . . . . . 10

2.2 Isolation of Rat Peritoneal Macrophages . . . . . . . . . . . 11

2.3 Co-culture of Macrophages and Cardiac Myocytes. . . . . . . . . . . 12

2.4 Measurement of Cardiac Myocyte Fractional Shortening. . . . . . . . 12 
2.5 Measurement of the Number of Macrophages Adherent to Myocytes. . 13

2.6 ELISA for ICAM-1 and VCAM-1 Expression. . . . . . . . . . . 13

2.7 Experimental Protocols . . . . . . . . . . . . . . . . . . . . 14

2.7.1 Fractional shortening of myocytes . . . . . . . . . . . 14

2.7.2 Macrophage adherence to myocytes. . . . . . . . . . 15

2.7.3 Role of macrophage adhesion on myocyte function . . . . . . 15

2.7.4 The role of $T N F \alpha$, oxygen free radicals, NO, and peroxynitrite . . 15

2.8 Data Analysis. . . . . . . . . . . . . . . . . . . . . . . 16

CHAPTER 3: RESULTS . . . . . . . . . . . . . . . . . . . . 18

3.1 Fractional Shortening. . . . . . . . . . . . . . . . . 18

3.2 Adherence of Macrophages . . . . . . . . . . . . . . . . . . 19

3.3 Role of Macrophage Adhesion on Myocyte Function. . . . . . . . . . . 19

3.4 The Role of TNF $\alpha$, Oxygen Free Radicals, NO, and Peroxynitrite . . . . 19

CHAPTER 4: DISCUSSION . . . . . . . . . . . . . . . . 26

4.1 Fractional Shortening . . . . . . . . . . . . . . 26

4.2 Role of Macrophage Adherence on Myocyte Function . . . . . . . . . 27

4.3 Role of Oxygen Free Radicals and Nitric oxide on Myocyte Function. . 28

4.4 Further Studies . . . . . . . . . . . . . . . . . . . . . . . . . . . 29

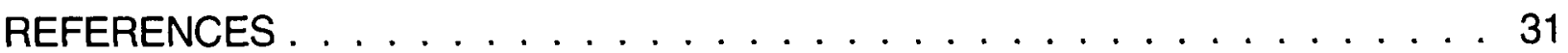




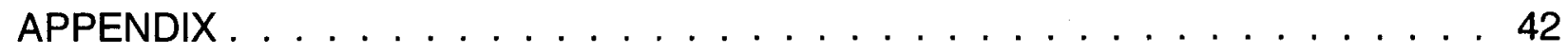

1 EXPERIMENTAL DATA . . . . . . . . . . . . . . 42

II . STATISTICAL ANALYSES. . . . . . . . . . . . . 56 


\section{LIST OF FIGURES}

Figure 1. Leukocyte binding via ICAM . . . . . . . . . . . 8

Figure 2. Systolic and diastolic frames of cardiac myocyte $\ldots \ldots \ldots$

Figure 3. Fractional shortening of cardiac myocyte . . . . . . . . . . . 21

Figure 4. Number of adherent macrophages to myocytes . . . . . . . . . . . 22

Figure 5. Optical density of ICAM-1 expression from ELISA . . . . . . . . . . 23

Figure 6. Fractional shortening of myocytes with antibodies . . . . . . . . . . 24

Figure 7. Fractional shortening of myocytes after exposure to inhibitors . . . . . . 25 


\section{LIST OF TABLES}

Table 1. Inclusion criteria for patients with sepsis. . . . . . . . . . . . . 2 


\section{LIST OF ABBREVIATIONS}

\begin{tabular}{ll} 
ABC & Avidin-Biotin Complex \\
BSA & Bovine Serum Albumin \\
ELISA & Enzyme-Linked Immunosorbent Assay \\
ICAM-1 & Intercellular adhesion molecule-1 \\
IL-1 $\beta$ & Interleukin-1 beta \\
LFA-1 & Lymphocyte function-associated antigen-1 \\
L-NAME & N-nitro-L-arginine methyl ester \\
LPS & Lipopolysaccharide \\
MCP-1 & Monocyte Chemotactic Protein-1 \\
MEM & Minimal Essential Media \\
NO & Nitric Oxide \\
OPD & 1,2-Phenylenediamine dihydrochloride \\
PBS & Phosphate-Buffered Saline \\
rTNF $\alpha$ & recombinant tumor necrosis factor-alpha \\
SIRS & Systemic Inflammatory Response Syndrome \\
SOD & Superoxide dismutase \\
TNF $\alpha$ & Tumor necrosis factor-alpha \\
VCAM-1 & Vascular cell adhesion molecule-1 \\
\hline
\end{tabular}




\section{ACKNOWLEDGEMENTS}

This work was supported by the Heart and Stroke Foundation of British Columbia and Yukon and by a British Columbia Medical Services Foundation Scholarship.

I would like to express my sincere thanks to Dr. Keith Walley for supervising this thesis. His constructive criticism, helpful suggestions, and patience provided me with the support and the guidance that made this work possible.

I would also like to extend my appreciation to Treena McDonald for her time and her helpful advice.

A special thank-you to Christine for her patience and help with statistics.

Finally, I would like to acknowledge Dr. Jen Yu and Betty Poon for teaching me cardiac myocyte isolation and culture techniques. 


\section{CHAPTER 1: INTRODUCTION}

\subsection{History of Septic Shock}

Sepsis is the presence of various pathogenic organisms and their toxins, in the blood or tissues while septic shock is defined as the system's response to an invasive infection caused by these organisms. The term "sepsis" comes from an old Greek term referring to putrefaction (1). Early physicians recognized the syndrome as a putrefactive process whereby a rotting or decaying odor was detected along with its systemic response (2). To the general population, sepsis was formerly known by its other more recognized name, "blood poisoning".

Septic shock is due to the spread of infection from an initial site to the systemic circulation. Some of the common causes of septic shock are:

1) Pneumonia and subsequent spread of a gram positive or gram negative infection.

2) Peritonitis, caused by the leak from the gut from an intestinal disease or wounds.

3) Infection spreading into the blood from the kidney or urinary tract, commonly caused by gram negative bacilli.

4) Post surgical wound infections.

5) Cutaneous or deeper gangrenous infection resulting from gram positive or anaerobic organisms spreading first through the tissues, then to the blood. 
Due to the multiple causes of septic shock, it is often difficult to categorize this condition. Common features are: high fever, high cardiac output, marked systemic vasodilatation, sludging of the blood, and development of microclots. Many studies on sepsis and septic shock have formulated a set of criteria for enrolling patients (Table 1). Patients are selected for sepsis trials if they are known or even suspected of having a gram-negative infection in addition to either fever or hypothermia, tachycardia or tachypnea. Patients must also have at least one of the signs of organ dysfunction such as hypoxemia, increased serum lactate concentration, decreased urine output, altered mental mentation and unexplained coagulation (3).

\section{Table 1: Inclusion criteria for patients with sepsis.}

I) Known or suspected gram-negative infection

Plus at least one of these signs:

a) Fever or hypothermia: $>38.2^{\circ} \mathrm{C}$ or $<36.5^{\circ} \mathrm{C}$

b) Tachycardia: $>90$ beats $/ \mathrm{min}$

c) Tachypnea: $>20$ breaths/min

II) Plus at least one of these signs of organ dysfunction:

a) Hypoxemia: $\mathrm{PaO}_{2} / \mathrm{FIO}_{2} \leq 280$

b) Increased serum lactate concentration: above normal value

c) Oliguria: $<0.5 \mathrm{~mL} / \mathrm{kg}$ of body weight $/ \mathrm{hr}$

d) Altered mentation: Glasgow Coma Scale $<15$, or decrease $\geq 1$

e) New coagulopathy: Unexplained 


\subsection{Statistics of the Septic Shock Syndrome}

Septic shock syndrome, which is the most frequently recognized cause of morbidity in the postoperative period (4), has been estimated to occur in $1 \%$ of all hospitalized patients, affecting more than 40,000 people in Canada every year (5). There has been a steady increase in these numbers, which has been attributed to the recent advances in surgical and medical treatments such as aggressive chemotherapy, the use of immunosuppressive drugs for organ transplantation, the increased survivability of patients, and the use of invasive medical procedures (6). Mortality rates in patients suffering from this septic shock range from $20-30 \%$. Treatment of patients with septic shock usually consists of aggressive antibiotic therapy and surgical intervention. Unfortunately, in many cases these treatments are not enough (7). Many times, physicians treating individuals have been puzzled over the mechanism by which shock and tissue injury, resulting from complications due to sepsis, may fatally progress in some cases, even after the patient's infection has been appropriately treated (12).

In $40 \%$ of cases, sepsis is complicated by cardiovascular dysfunction, causing a dramatic increase in the mortality rate, anywhere from $40-70 \%$ (7). Ejection fraction, which is a measure of contractility, is decreased in septic humans and recovers to normal values over approximately ten days $(9,38)$. Similar reductions in ejection fraction (39) and in loadinsensitive indexes of ventricular contractility $(26,40)$ have been observed in animal models of sepsis. One important and often observed characteristic of this cardiovascular dysfunction is the decrease in left ventricular contractility (8). Unfortunately, the cause of 
decreased contractility is not fully understood. One popular theory is that a circulating myocardial depressant factor is released during sepsis since plasma from septic humans and pro-inflammatory cytokines can cause decreased myocyte shortening $(8,9,12)$. Endotoxin or products from bacterial cells trigger the inflammatory cascade by activating monocytes and macrophages. These cells then elaborate a number of cytokines including TNF $\alpha$ (tumor necrosis factor-alpha) and IL-1 $\beta$ (interleukin-1 beta). Several studies have implicated TNF $\alpha$ as a systemic soluble mediator that is important in sepsis and septic shock $(10,11)$. These cytokines then activate cells which are involved in the inflammatory process such as neutrophils and endothelial cells. Oxygen free radicals, which have been documented to be released from macrophages and neutrophils, have been shown to represent another pathway for tissue damage. This inflammatory cascade during sepsis can cause significant damage to the vascular and capillary bed structure and function, tissue damage, edema, and cell death by hypoxia (12).

\subsection{Previous Research}

Although the term "sepsis" is related to the bacterial infection, recent studies have proposed that the problems associated with sepsis may not be caused by the invading organism. They propose that the development of sepsis is due to the body's immunological response to the event, which occurs when mediators such as TNF $\alpha$ and IL-1 $\beta$ are released (1). It has been proposed that a more general term, called Systemic Inflammatory Response Syndrome (SIRS), be employed in order to describe the clinical manifestation of systemic inflammation (13). 
Macrophages have been shown to play an essential part of the immune response to sepsis by presenting antigens to lymphocytes during the development of specific immunity, ingesting and destroying invading micro-organisms, serving as accessory cells to lymphocytes, and as the source of several soluble factors involved in host defense (14). The transformation from resident bone marrow-derived monocytes to tissue macrophages is an important step in its maturation process. In responding to an invading microorganism, tissue macrophages undergo a conversion from a normal resting macrophage to an activated macrophage. These activated cells are usually larger, have an increased capacity for adherence, are more metabolically active, and more able to release soluble substances and oxidative metabolites. Macrophages, when exposed to endotoxin (lipopolysaccharide; LPS), release cytokines such as TNF $\alpha$, which can activate other macrophages $(23-26,43)$. This raises the possibility that during sepsis, LPS-exposed macrophages, located at sites of infection, may self-activate (14). LPS has been shown on many occasions to induce septic shock by the stimulation of these macrophages $(11,15)$

Macrophages have been discovered in the heart after ischemia-reperfusion $(16,17)$; in inflammatory cardiomyopathies (18-20), after orthotopic heart transplantation (21); and in animal models of sepsis after injection of endotoxin $(57,58)$. In a related inflammatory state in patients who underwent orthotopic heart transplantation, a significant increase in macrophage infiltration of the heart was observed along with a corresponding increase in TNF $\alpha$ production (28). Leukocytes also have been shown to contribute to decreased myocardial contractility after endotoxin infusion (22) but whether the macrophage subset 
contributes to the inflammatory process is not known. Activated leukocytes have been shown to decrease left ventricular function (43). In animal models of sepsis, leukocytes are slowed and retained in myocardial capillaries (51). This is associated with capillary endothelial and cardiac myocyte damage, myocardial edema (41), and decreased contractility (22). Similarly, leukocytes decrease contractility in animal models of ischemiareperfusion (52).

TNF $\alpha$ has been implicated as a systemic soluble mediator which is important in sepsis and septic shock $(10,11)$. TNF $\alpha$ administered alone in whole animal models $(24,26)$ or as one of the mediators released after endotoxin infusion (44), results in a decrease in ventricular contractility within $4-6$ hours $(24,26,44)$. In rats, injections of recombinant TNF $\alpha$ led to severe hypotension, lactic acidosis and shock within minutes (11). These effects were blocked when animals were pre-injected with antibodies to TNF $\alpha(30)$. TNF $\alpha$ has also been shown to induce the release of IL- $1 \beta$ from endothelial cells and macrophages while IL-1 $\beta$ subsequently stimulates the biosynthesis of other cytokines (10). TNF $\alpha$ may also act synergistically with IL-1 $\beta$ (43) and appears to decrease myocardial contractility by activation of other mediator pathways $(23,26)$. This would indicate that TNF $\alpha$ and IL-1 $\beta$ both play early roles in the body's inflammatory response to infection, since the fever associated with the early stages of sepsis, has been found to be, at least, partly induced by IL-1 $1 \beta . \mathrm{IL}-1 \beta$, which is produced by blood monocytes and tissue macrophages, has a particularly potent effect on the inflammatory response (31). In the response of the host 
to sepsis, IL-1 $\beta$ is a non-specific mediator of the acute phase response.

A number of investigators have shown that part of the effect of pro-inflammatory cytokines in vitro is due to stimulation of nitric oxide production in cardiac myocytes $(23,27,45,46)$. The release of TNF $\alpha$ and nitric oxide from macrophages is known to contribute to myocardial dysfunction (23-29). Similarly, in isolated working hearts, TNF $\alpha$ and IL-1 $\beta$ contribute to decreased contractile function via nitric oxide and peroxynitrite (47). Thus, cytokine mediators released from macrophages may contribute to myocardial dysfunction in sepsis. Therefore, a role for intramyocardial macrophages in myocardial depression is plausible since macrophages could potentially contribute to both mediator and leukocyteinduced myocardial depression, although very little is known about their interaction with cardiac myocytes.

Antibody to TNF $\alpha$ decreases the functional impairment induced by ischemia-reperfusion (48). Ischemia-reperfusion upregulates expression of mRNA for the pro-inflammatory cytokines TNF $\alpha$ and IL-1 $\beta$ in the heart (49). In isolated rat hearts, myocardium releases significant amounts of TNF $\alpha$ after ischemia-reperfusion (17). TNF $\alpha$ release in ischemiareperfusion is associated with the accumulation and activation of macrophages (42). TNF $\alpha$ may contribute to further leukocyte accumulation by stimulation of chemokine production (34) and upregulation of leukocyte adhesion molecules on cardiac myocytes (50). 
Intercellular adhesion molecule-1 (ICAM-1) is a cell-surface antigen for lymphocyte function-associated antigen-1 (LFA-1) (Figure 1). Cytokine induction of this adhesion molecule on cardiac myocytes may be a critical step in myocarditis (32). Smith et al. have shown that canine cardiac myocytes synthesize and express ICAM-1 on their membrane and that this receptor allows neutrophils to adhere. When exposed to IL-1 $\beta$, TNF $\alpha$ or LPS, neutrophil adhesion was significantly increased and that this adherence can be blocked by anti-ICAM-1 (33).

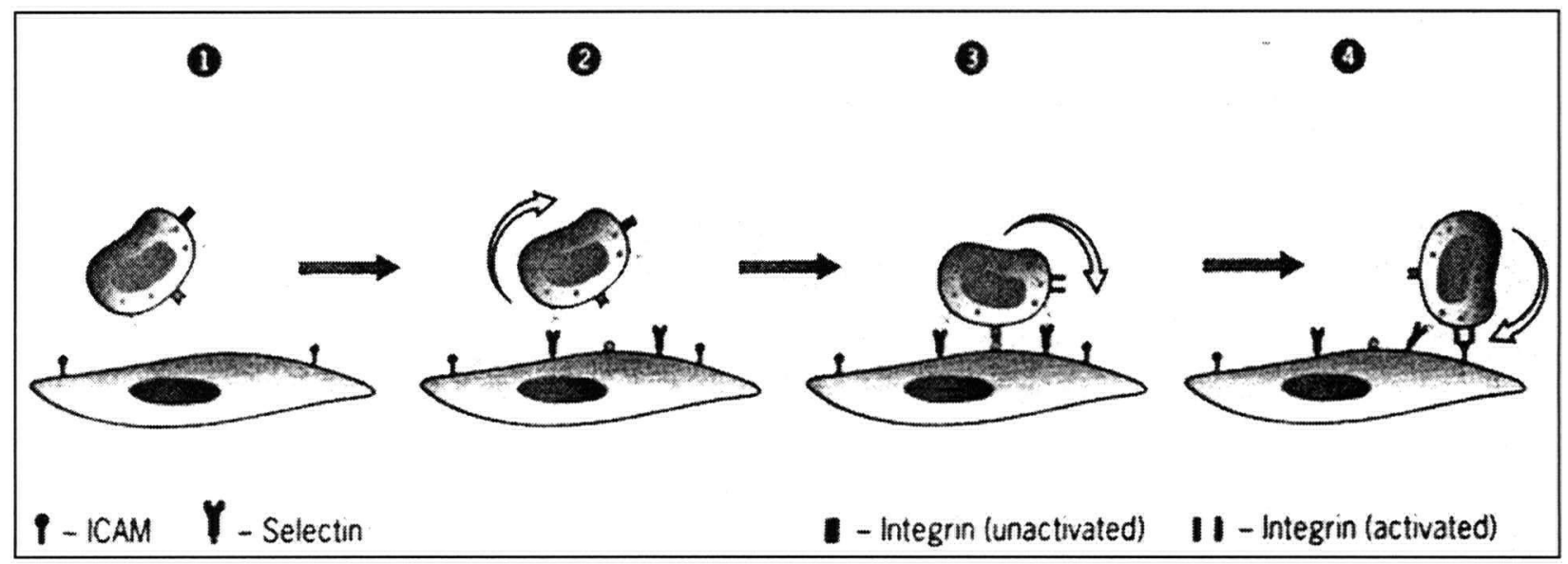

Figure 1: Steps in the adhesion of leukocytes via ICAM. (1) expression of ICAM receptors (2) leukocyte trapping, (3) leukocyte activation of integrin receptors, 4) leukocyte adhesion. Adapted from Gerald Karp: Cell and molecular biology: concepts and experiments, John Wiley \& Sons, Inc., 1996. 
By co-incubating isolated ventricular myocytes with a variety of cytokines, one is in a better position to observe the accumulation and adhesion of leukocytes to cardiac myocytes, as opposed to whole heart experiments. Massey et al. have shown that cardiac myocytes directly recruit activated leukocytes into areas of injury (34). These cell culture studies have shown that myocytes play an important role in the pathogenesis of inflammation-mediated myocardial injury such as ischemia/reperfusion. Their unique morphology (rod shaped, striated) allows them to not only be easily differentiated from non-myocytes, but their functional properties can also be easily measured. Other studies have shown that by studying leukocyte migrations in isolated cultures, it may aid in understanding the mechanisms whereby these cells are brought in close proximity to myocytes where secretory products would have enhanced injurious effects, particularly if leukocyte adherence to myocytes occurs (35).

Our goal was to determine whether macrophages could alter cardiac myocyte function. To address this issue, we first co-cultured rat ventricular cardiac myocytes and rat peritoneal macrophages with various inflammatory mediators and measured cardiac myocyte contractile function. Interestingly, we noted that decreased myocyte contractile function was associated with adhesion of macrophages to myocytes. This led to the examination of macrophage adhesion to myocytes and the role of receptor-mediated adhesion in myocyte contractile dysfunction. Finally we investigated the potential mechanisms whereby adherent macrophages could mediate myocyte contractile dysfunction, including TNF $\alpha$, reactive oxygen intermediates, and nitric oxide production. 


\section{CHAPTER 2: METHODS}

This study was approved by the University of British Columbia Animal Care Committee and adheres to Canadian and $\mathrm{NIH}$ guidelines for animal experimentation.

\subsection{Isolation of Rat Ventricular Myocytes}

Male Sprague-Dawley rats $(250-300 \mathrm{~g})$ were anesthetized with $3 \%$ halothane by inhalation and 1000 units of heparin (Organon Teknika, Canada) were injected intraperitoneally in order to prevent the blood from clotting. Ten minutes later a midline thoracotomy was performed and the heart was excised and placed in oxygenated $\left(95 \% \mathrm{O}_{2}, 5 \% \mathrm{CO}_{2}\right)$ HEPES-Joklik modified calcium-free MEM buffer (minimal essential media, Gibco BRL, Grand Island, NY) at $0^{\circ} \mathrm{C}$. Within two minutes, the heart was mounted, via the aorta, on a modified Langendorff apparatus and perfused with oxygenated MEM, at $37^{\circ} \mathrm{C}$ for 2 minutes. After blood in the coronary circulation was cleared, the perfusate was changed to $30 \mathrm{~mL}$ recirculating calcium free MEM containing $1 \mathrm{mg} / \mathrm{mL}$ of $236 \mathrm{U} / \mathrm{mL}$ collagenase (type 2, Worthington Biochemical, Freehold, NJ). At 15 and 20 minutes, the calcium concentration was increased, stepwise to 25 and $75 \mu \mathrm{mol} / \mathrm{L}$ by adding $75 \mu \mathrm{L}$ and $150 \mu \mathrm{L}$ of $10 \mathrm{mM} \mathrm{CaCl}_{2}$ respectively to the recirculating buffer. After a $30-40$ minute period of digestion the ventricles were removed from the perfusion system and gently teased apart. The tissue, in oxygenated $75 \mu \mathrm{mol} / \mathrm{L}$ calcium perfusion buffer, was then agitated for 2-3 minutes at $37^{\circ} \mathrm{C}$ in a water bath. The tissue and dispersed cells in solution were then filtered through a $200 \mu \mathrm{m}$ nylon mesh. The filtrate was then centrifuged at $500 \mathrm{rpm}$ for 2 
minutes and the supernatant was replaced with fresh perfusion buffer. The cells were then washed three times at $37^{\circ} \mathrm{C}$ in MEM containing increasing $\mathrm{Ca}^{2+}$ concentrations $(200 \mu \mathrm{M}$, $500 \mu \mathrm{M}$ and $1 \mathrm{mM}$ ), allowing the cells to settle by gravity for 10 minutes between each wash. Cells were resuspended in $37^{\circ} \mathrm{C}$ HEPES-modified M199 buffer ( $\mathrm{pH} 7.4$ ) (Gibco BRL) with 1\% BSA (bovine serum albumin, (98\% purity) Sigma Chemicals, St. Louis, MO) and viable cell concentration was determined using a hemocytometer. The cell concentration was adjusted to 50,000 cells $/ \mathrm{mL}$. 5000 cells were loaded into each well of

a laminin-coated 96 well plate (VWR Canlab, Canada) and incubated at $37^{\circ} \mathrm{C}$ with $95 \% \mathrm{O}_{2}$ and $5 \% \mathrm{CO}_{2}$. At 90 minutes, the media was changed to fresh $\mathrm{M} 199$ with BSA and incubated for 24 hours. Cells were considered viable if they demonstrated a characteristic rod shape without cytoplasmic blebbing. This morphometric assessment of viability was confirmed in a subset of experiments with trypan blue exclusion. We found that the fraction of viable myocytes was always greater than $85 \%$.

\subsection{Isolation of Rat Peritoneal Macrophages}

Ten $\mathrm{mL}$ of sodium caseinate was injected intraperitoneally in rats anesthetized using $3 \%$ halothane by inhalation. (59) The rats were allowed to recover and 72 hours later were again anesthetized using 3\% halothane by inhalation. Peritoneal lavage was performed using 3 aliquots of $30 \mathrm{~mL}$ normal saline containing $1 \mathrm{U} / \mathrm{mL}$ heparin at $37^{\circ} \mathrm{C}$. Peritoneal lavage fluid was then filtered through sterile gauze into $50 \mathrm{~mL}$ tubes. Cells were then centrifuged at $1700 \mathrm{rpm}$ for $6 \mathrm{~min}$. The pellet was resuspended in 4 times volume of 0.144 $\mathrm{mol} / \mathrm{L} \mathrm{NH}{ }_{3} \mathrm{Cl}$ solution to lyse any red blood cells. The macrophages were centrifuged again, 
and then resuspended in M199 buffer containing 1\% BSA. After a final centrifugation, the pellet was resuspended in M199 buffer with BSA and the concentration of macrophages was determined using a hemocytometer. The concentration of macrophages was then adjusted to 500,000 cells $/ \mathrm{mL}$. The percentage of macrophages was found to be $90-95 \%$ and these cells were viable as indicated by trypan blue exclusion.

\subsection{Co-culture of Macrophages and Cardiac Myocytes}

After 24 hours of cardiac myocyte incubation, 50,000 macrophages were added to each well of cardiac myocytes (ratio of 10 macrophages per cardiac myocyte (33) in the 96 well laminin-coated plates for co-culture experiments. These co-cultures were incubated at $37^{\circ} \mathrm{C}$ in $95 \% \mathrm{O}_{2}, 5 \% \mathrm{CO}_{2}$ for 4 hours. After the 4 hour incubation, fractional shortening of electrically stimulated myocytes and the number of adhering macrophages per myocyte was determined.

\subsection{Measurement of Cardiac Myocyte Fractional Shortening}

Fifteen minutes before the 4 hour time point, $2 \mu \mathrm{L}$ of trypsin $(0.5 \% \mathrm{w} / \mathrm{v})$ was added to each well in order to cleave the myocytes off the laminin-coated bottom. The plates were then returned to the incubator for the final fifteen minutes. Preliminary experiments demonstrated that this concentration of trypsin did not alter cell viability and cleaved more than $95 \%$ of the adherent myocytes from their attachments to the bottom of the well. At the 4 hour time point, specially designed platinum electrodes were lowered into each well in the 96 well plate and the cardiac myocytes were electrically stimulated (Grass S48 
stimulator, W. Warwick, RI, 45 volts, 2.2 ms duration, $25 \Omega$ resistance) while being recorded by videomicroscopy (Sony SLV-760HF) (Figure 2). This electrical stimulus was chosen from preliminary threshold experiments as twice the minimum electrical stimulus required to maximally contract the cardiac myocytes. Still frames of systolic and diastolic myocytes were captured for computer analysis from the video recording and myocyte fractional shortening was then measured using Scion ImagePC (Scion Corporation, Frederick, MD).

\subsection{Measurement of the Number of Macrophages Adherent to Myocytes}

In similar experiments, myocytes and macrophages were co-incubated for 4 hours and the number of adherent macrophages was counted for all myocytes in 12 wells at five random microscope fields per well.

\subsection{ELISA for ICAM-1 and VCAM-1 Expression}

The cardiac myocyte culture without added macrophages was challenged with human recombinant tumor necrosis factor-alpha (rTNF $\alpha$, R\&D Systems, Minneapolis, MN) in concentrations of $0-50 \mathrm{ng} / \mathrm{mL}$ for 4 hours. ICAM- 1 and VCAM-1 expression was then quantified by ELISA. Briefly, after the 4 hour incubation cells were fixed using $4 \%$ paraformaldehyde ( $100 \mu /$ well) for 10 minutes at room temperature and then washed twice with $1 \mathrm{x}$ PBS and stored at $4^{\circ} \mathrm{C}$ until the ELISA. Plates were then washed twice with $1 \mathrm{x}$ PBS and blocked by adding $250 \mu \mathrm{L} /$ well of $5 \%$ normal goat serum (Dako Diagnostics Canada, Mississauga, ON) in PBS for one hour at $37^{\circ} \mathrm{C}$. Then, $100 \mu /$ well of rabbit anti-rat ICAM-1 or rabbit anti-rat VCAM-1 (gift from Dr. P. Ward, University of Michigan), diluted 
to 1:5000 in PBS was added, and incubated for one hour at $37^{\circ} \mathrm{C}$, following a PBS wash. Cells were washed and $100 \mu \mathrm{L} /$ well of a biotinylated goat anti-rabbit (Dako Diagnostics Canada, Mississauga, ON), diluted 1:5000 in PBS, was added and incubated at $37^{\circ} \mathrm{C}$ for 30 minutes. Then ABC complex (Dako Diagnostics Canada, Mississauga, ON) was added followed by chromogen substrate (OPD, Dako). The colorimetric reaction was quenched by the addition of $0.5 \mathrm{~mol} / \mathrm{L} \mathrm{H}_{2} \mathrm{SO}_{4}$, according to the manufacturer's instructions. Plates were then read at $490 \mathrm{~nm}$ using a microplate reader (Rainbow Reader, SLT Lab Instruments, Salzburg, Austria).

\subsection{Experimental Protocols}

\subsubsection{Fractional shortening of myocytes.}

We studied 1) cultures of cardiac myocytes alone, 2) cultures of cardiac myocytes with macrophages added into a culture well insert $(0.45 \mu \mathrm{m}$ pores so that myocytes and macrophages were cultured in the same well but the cells were kept separated), and 3) cocultures of cardiac myocytes and macrophages where cell interaction was not prevented. TNF $\alpha(2 \mu \mathrm{L})$, LPS (lipopolysaccharide, $2 \mu \mathrm{L})$, or control saline $(2 \mu \mathrm{L})$ was added to each well at the start of the cardiac myocyte-macrophage co-culture. The final concentration of TNF $\alpha$ and endotoxin in the wells was $20 \mathrm{ng} / \mathrm{mL}$ and $10 \mu \mathrm{g} / \mathrm{mL}$ respectively. At the end of a 4 hour incubation, one microscope field was randomly selected in each well and was electrically stimulated once. Previous experiments showed that more than one stimulation of the myocytes would render them inactive. Generally, 1 to 4 myocytes were present in each field. Diastolic length and fractional shortening were determined for each myocyte. 


\subsubsection{Macrophage adherence to myocytes.}

Co-cultured myocytes and macrophages were challenged using TNF $\alpha$, IL-1 $\beta$, LPS, or vehicle. TNF $\alpha$ and IL-1 $\beta$ were added at a concentration of $20 \mathrm{ng} / \mathrm{mL}$ (28) while LPS was added at $10 \mu \mathrm{g} / \mathrm{mL}$ at the start of the 4 hour co-culture. Then the number of adherent macrophages to myocytes was counted by morphological assessment as well as observing their adhesion during myocyte contraction. In additional experiments to determine the role of adhesion molecules expressed by cardiac myocytes, antibodies to ICAM-1 and VCAM-1 were added at $200 \mathrm{pg} / \mathrm{mL}$ immediately prior to stimulation with TNF $\alpha$. The number of macrophages adherent to myocytes after 4 hours was counted.

\subsubsection{Role of macrophage adhesion on myocyte function.}

We repeated the co-culture experiments using pre-treatment with antibody to ICAM-1. TNF $\alpha(20 \mathrm{ng} / \mathrm{mL}), \mathrm{IL}-1 \beta(20 \mathrm{ng} / \mathrm{mL})$, LPS $(10 \mu \mathrm{g} / \mathrm{mL})$ (28), or control saline was immediately added and incubated for the 4 hour period. Fractional shortening of cardiac myocytes and the number of adherent macrophages were then measured.

\subsubsection{The role of TNF $\alpha$, oxygen free radicals, NO, and peroxynitrite.}

In order to assess the role of TNF $\alpha$, oxygen free radicals, NO, and peroxynitrite we used the same co-culture as previously described. Anti-TNF $\alpha$, oxygen free radical scavengers desferoxamine (0.6568 mg/mL (36)) and superoxide dismutase (SOD, $23.3 \mu \mathrm{g} / \mathrm{mL}(36)$ ), the NO synthase inhibitor L-NAME $\left(10^{-4} \mathrm{~mol} / \mathrm{L}(23)\right)$, and the peroxynitrite inhibitor urate 
(100 $\mu \mathrm{g} / \mathrm{mL}$ (37)) were added to co-cultures just prior to challenging with TNF $\alpha(20 \mathrm{ng} / \mathrm{mL}$ ) or saline. Urate was used since peroxynitrite being part of the nitric oxide synthase cascade. At 4 hours of co-culture fractional shortening was measured along with the number of adherent macrophages per cardiac myocyte.

\subsection{Data Analysis}

We tested for differences in fractional shortening and number of adherent macrophages using an analysis of variance choosing $p<0.05$ as significant. When a significant difference was found we identified specific differences between groups using a sequentially rejective Bonferroni procedure. Data are expressed as mean \pm standard error throughout. 


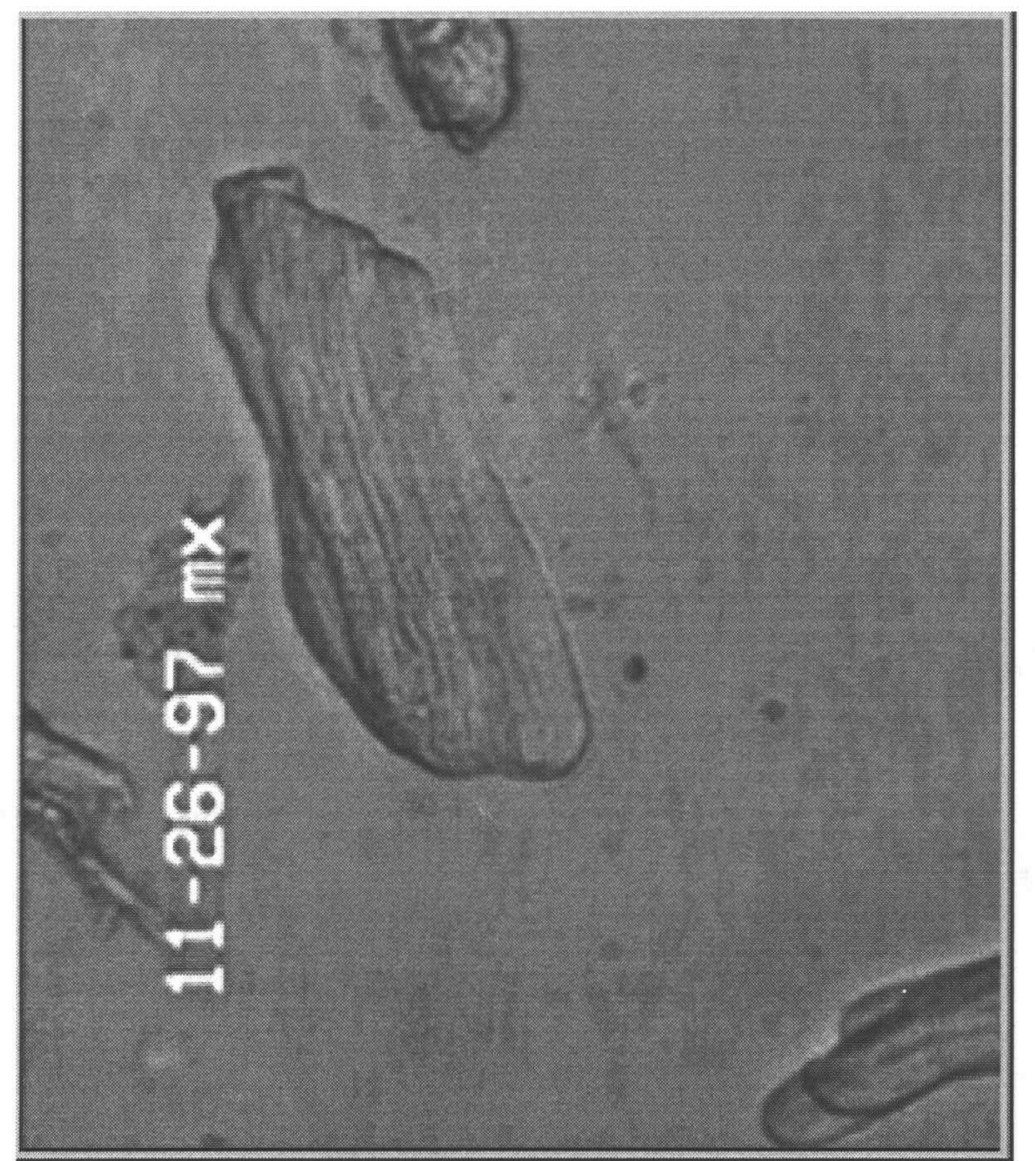

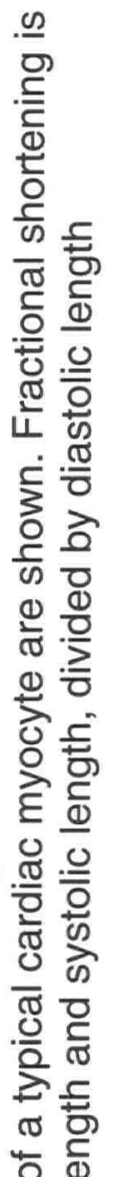

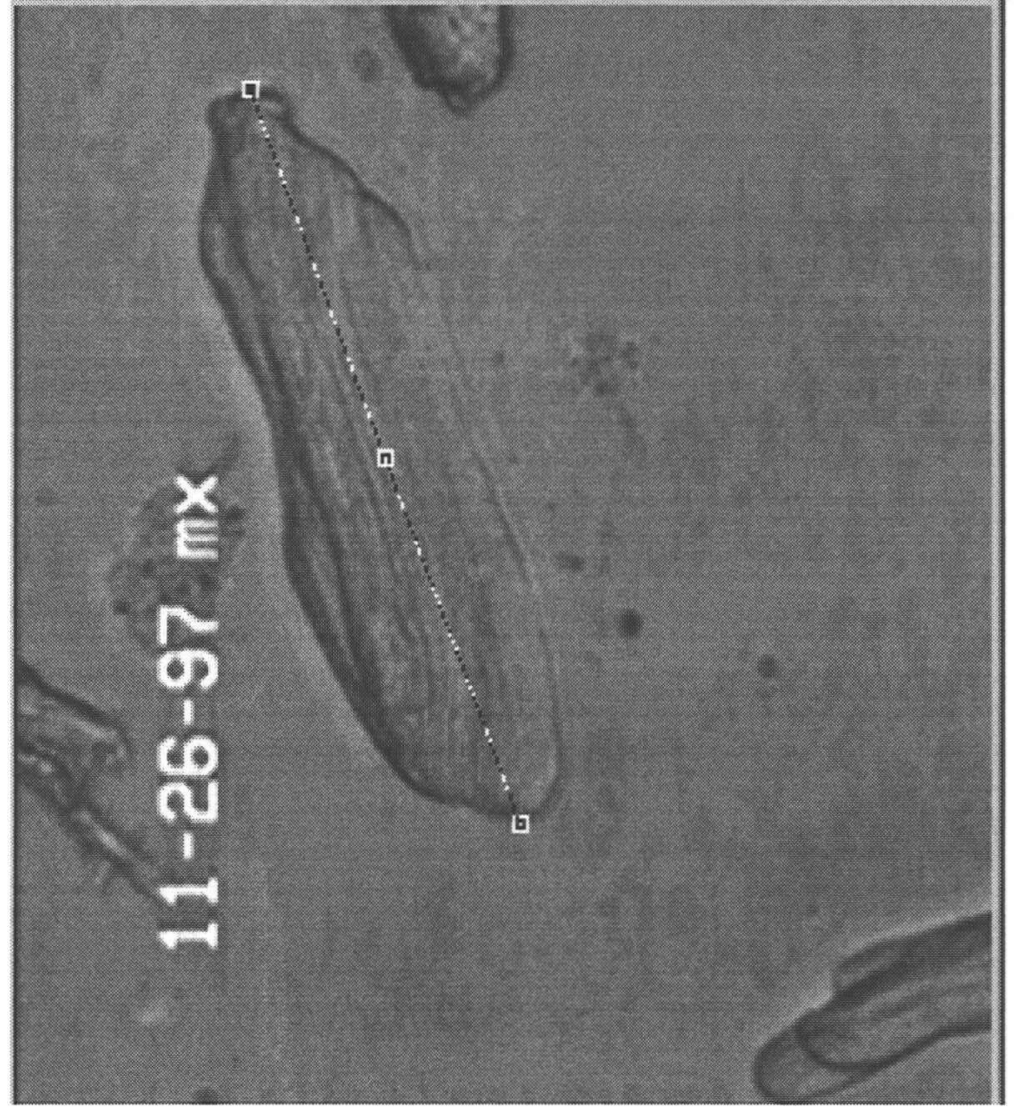

क 으

으으

है त

듬

응 등

응

代

잉

임

हิํํㅇ

윽 $\frac{1}{0}$

응

옹

के ल

으 임

음. 들

원

匹

ำ

N

$\frac{\amalg}{\frac{\varpi}{\square}}$ 


\section{CHAPTER 3: RESULTS}

\subsection{Fractional Shortening}

Fractional shortening of myocytes alone exposed to TNF $\alpha$ or LPS was no different from unchallenged myocytes (Figure 3). Similarly, when myocytes were cultured with macrophages but physical contact was prevented by placing macrophages in culture well inserts, neither TNF $\alpha$ nor LPS had a statistically significant effect on fraction shortening (Figure 3). Fractional shortening of myocytes in co-culture with macrophages (no well inserts) without activation was not statistically different from unchallenged myocytes alone (Figure 3). However, TNF $\alpha$ and LPS added to macrophage-myocyte co-cultures decreased myocyte fractional shortening by $24 \pm 8 \%(p<0.05)$ and $26 \pm 9 \%(p<0.05)$ respectively (Figure 3). The diastolic length of myocytes in co-cultures was not significantly altered by TNF $\alpha$ or LPS indicating that the decrease in fractional shortening was due to a change in systolic contractility and not due to varying myocyte lengths. In these experiments, the number of adherent macrophages was significantly greater in co-cultures challenged with TNF $\alpha$ and LPS $(4.2 \pm 0.2)$ than in unchallenged co-cultures $(2.6 \pm 0.3)$ $(p<0.05)$ and, as the number of adherent macrophages increased from 2 to 6 per cardiac myocyte, fractional shortening of the cardiac myocyte decreased by $0.7 \%$ per adherent macrophage $(p=0.07)$. Thus, macrophage adhesion appeared to be important in decreasing myocyte function. 


\subsection{Adherence of Macrophages}

Anti-ICAM-1 prevented increased adherence of macrophages to cardiac myocytes induced by TNF $\alpha$, IL-1 $\beta$, and LPS (Figure 4). Anti-VCAM-1 did not prevent increased adherence due to TNF $\alpha$, IL-1 $\beta$, or LPS in macrophage-myocyte co-culture (data not shown). ELISA for ICAM-1 showed that when myocytes were challenged with human recombinant TNF $\alpha$, the expression of ICAM-1 on cardiac myocytes was dose dependent, reaching a plateau at a dose of $20 \mathrm{ng} / \mathrm{mL}$ of TNF $\alpha$ (Figure 5). TNF $\alpha$ did not induce measurable VCAM-1 expression on cardiac myocytes (data not shown).

\subsection{Role of Macrophage Adhesion on Myocyte Function}

To determine if ICAM-1 mediated adhesion played a role in causing the decrease in cardiac myocyte function induced by activated macrophages, we added anti-ICAM-1 to cocultures. Anti-ICAM-1 prevented the increase in adherence due to TNF $\alpha, I L-1 \beta$, and LPS challenge (Figure 4) and also the decrease in myocyte fractional shortening (Figure 6).

\subsection{The Role of TNF $\alpha$, Oxygen Free Radicals, NO, and Peroxynitrite}

To further understand how adherent macrophages decrease cardiac myocyte fractional shortening we first examined the role of TNF $\alpha$. Anti-TNF $\alpha$ prevented the decrease in cardiac myocyte fractional shortening (Figure 6) induced by TNF $\alpha$ or LPS challenge which might be due to the macrophages which produce TNF $\alpha$ when exposed to LPS. Interestingly, anti-TNF $\alpha$ also decreased adherence of macrophages to myocytes (Figure 
4) induced by TNF $\alpha, I L-1 \beta$, or LPS challenge. We then examined the role of oxygen free radicals, NO, and peroxynitrite, since these three are released by macrophages. As in previous experiments, TNF $\alpha$ challenge of macrophage-myocyte co-culture significantly decreased cardiac myocyte fractional shortening (Figure 7). This decrease was completely inhibited by desferoxamine, SOD, and L-NAME. Urate did not prevent the decrease in fractional shortening to a statistically significant degree. The number of adherent macrophages did not decrease to account for improved fractional shortening with desferoxamine, SOD, or L-NAME. 


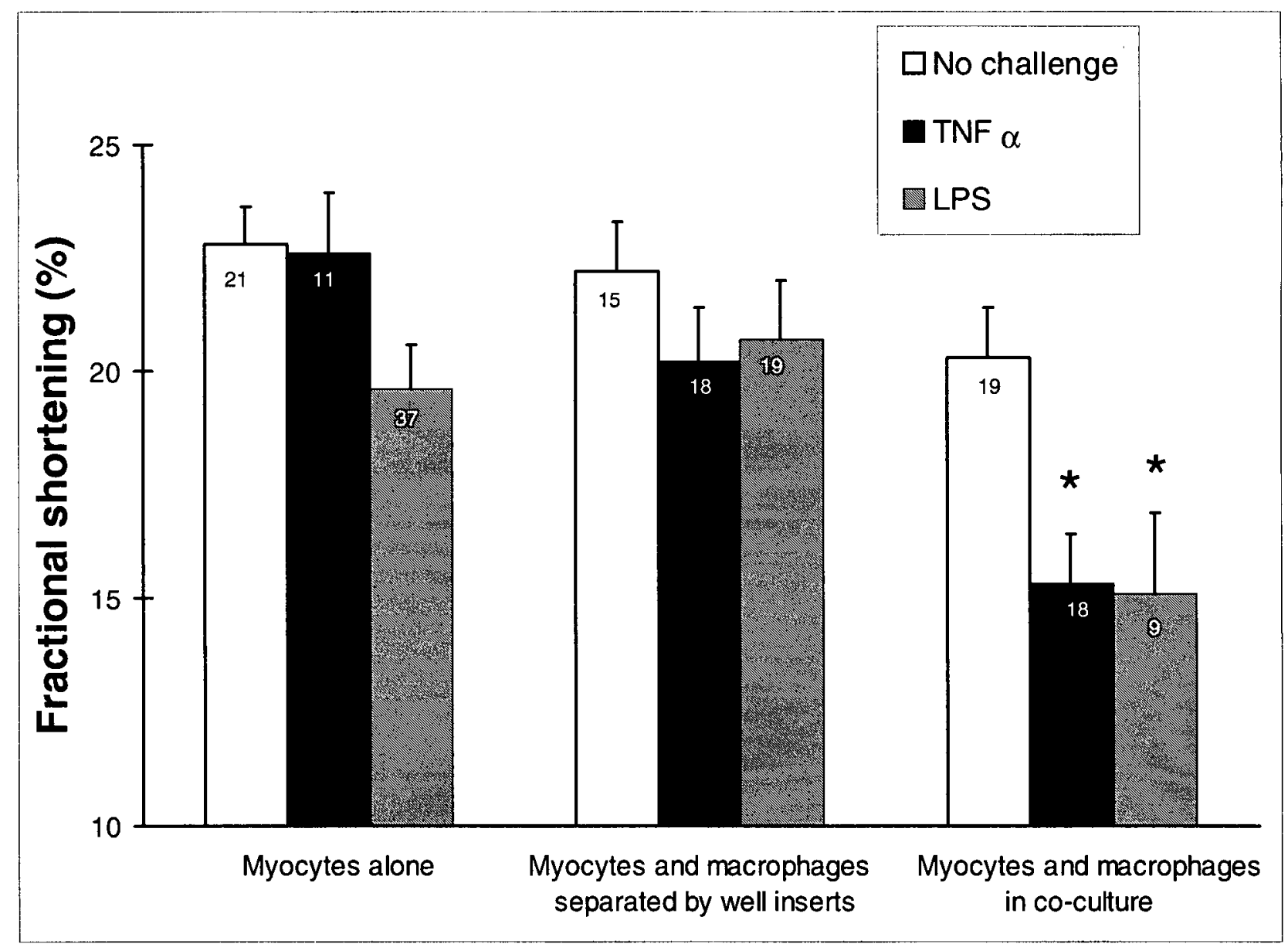

FIGURE 3- Fractional shortening of cardiac myocytes is shown, as determined by diastolic minus systolic, divided by diastolic. (* indicates $\mathrm{p}<0.05$ compared to all other groups, $\mathrm{n}$ is indicated on bars) 


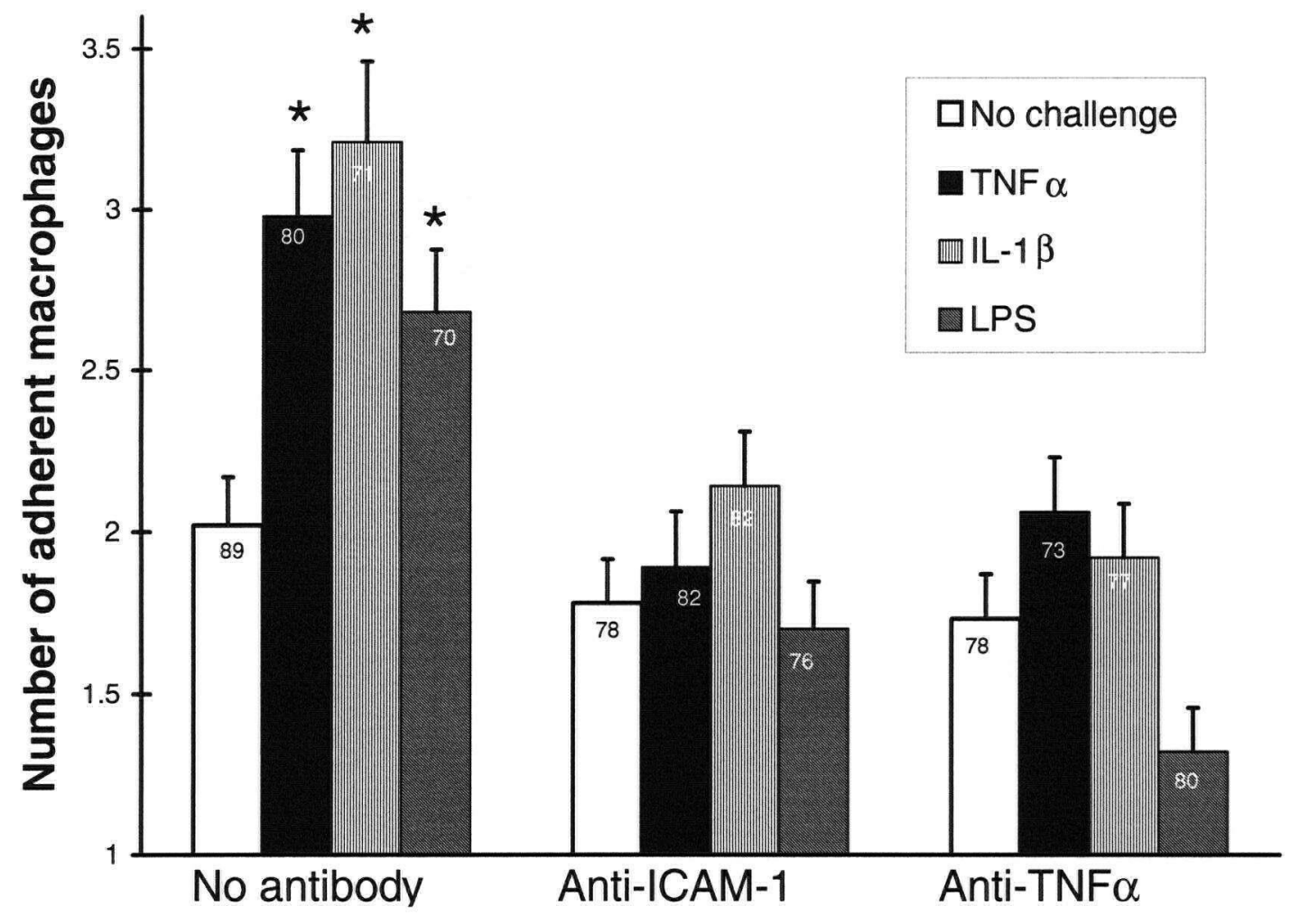

FIGURE 4-The number of macrophages adherent to cardiac myocytes after 4 hours of co-culture is shown. ${ }^{*}$ indicates $p<0.05$ compared to other groups, $n$ is indicated on bars) 


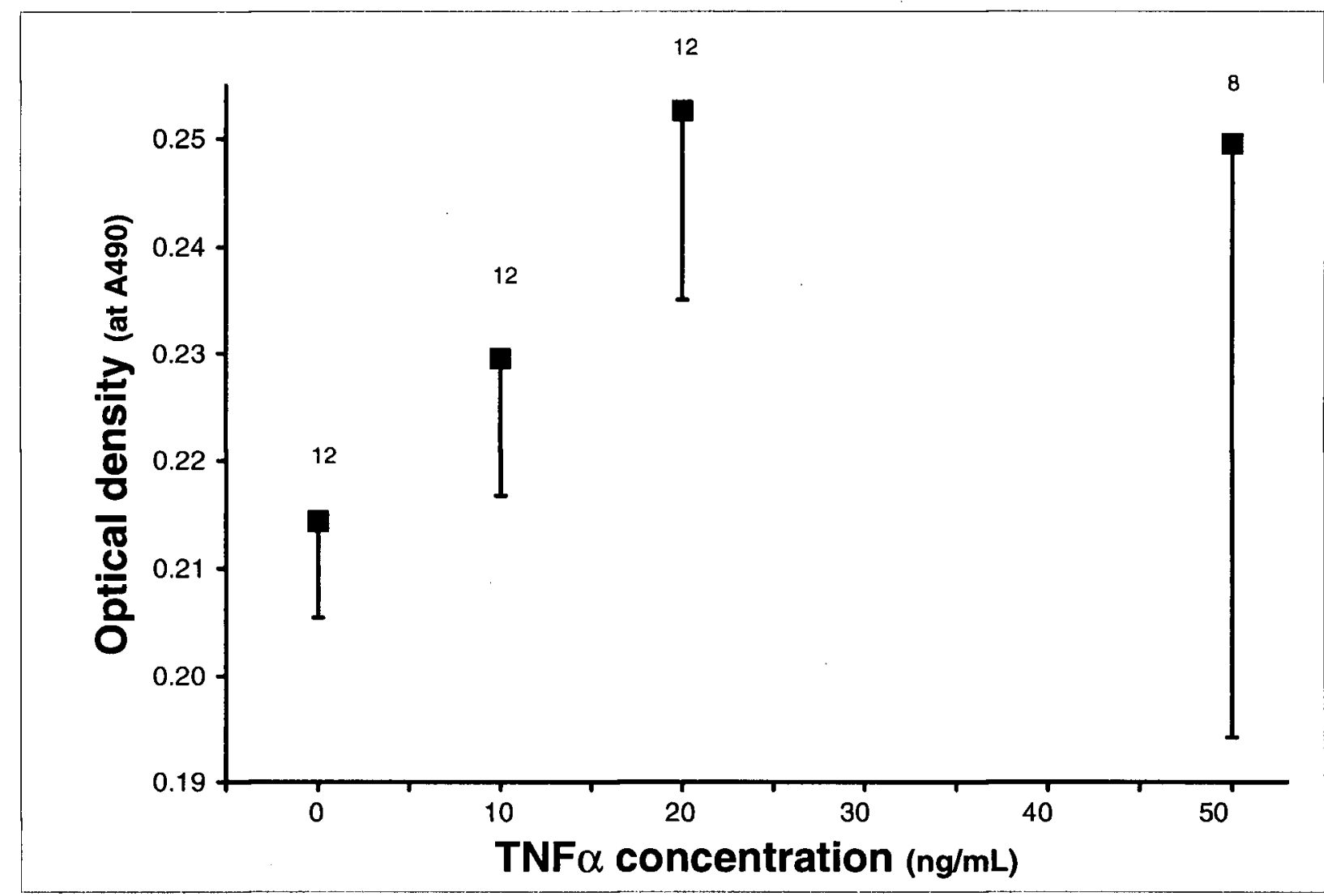

FIGURE 5-Optical density as determined by the ELISA for ICAM-1 expression on rat cardiac myocytes after 4 hours of TNF $\alpha$ challenge is shown. ( $n$ is indicated above) 


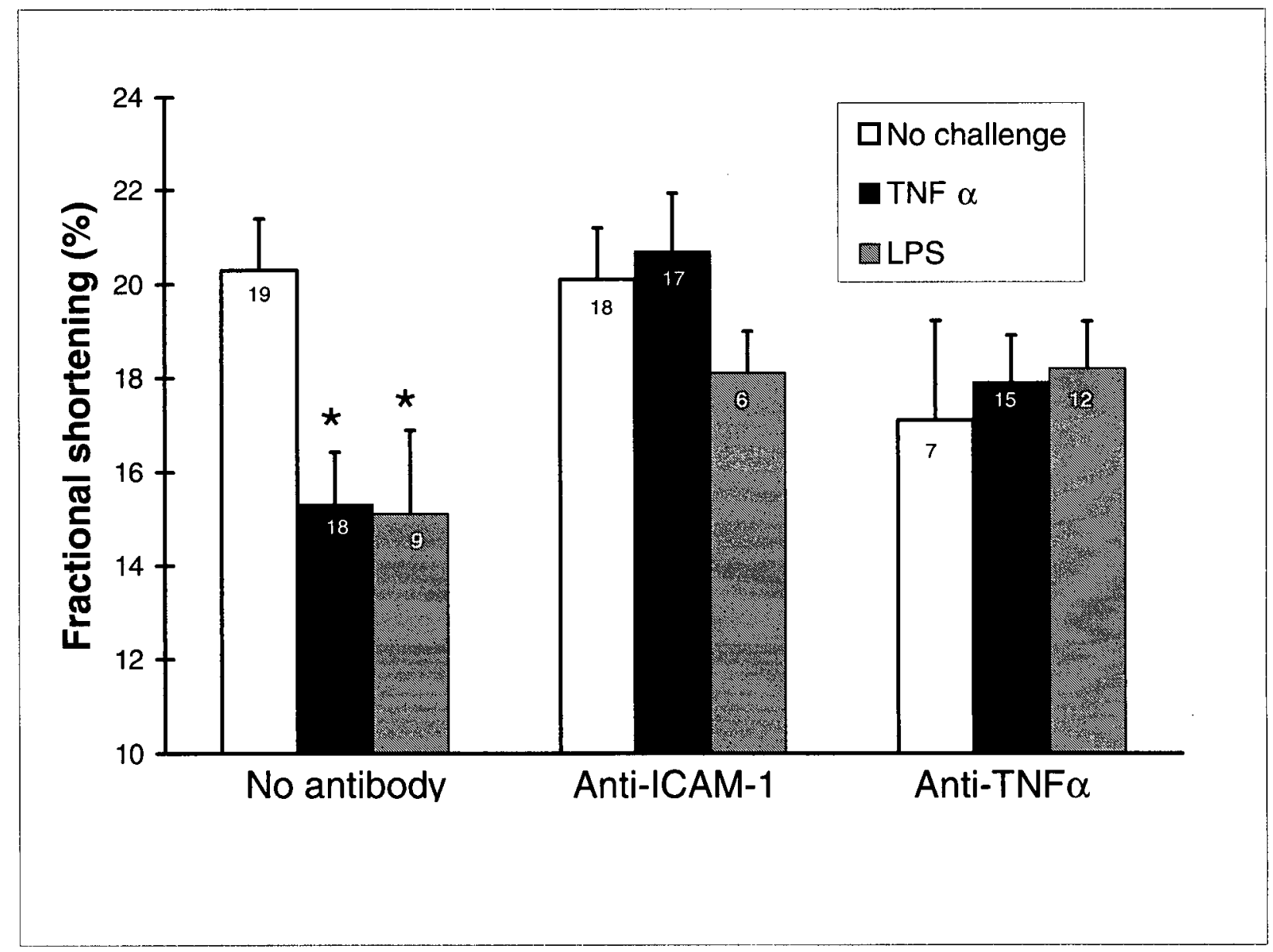

FIGURE 6-Fractional shortening of rat cardiac myocytes co-incubated with rat macrophages after 4 hour exposure to TNF $\alpha$ or LPS. ( ${ }^{*}$ indicates $p<0.05$ compared to control, $\mathrm{n}$ is indicated on bars). 


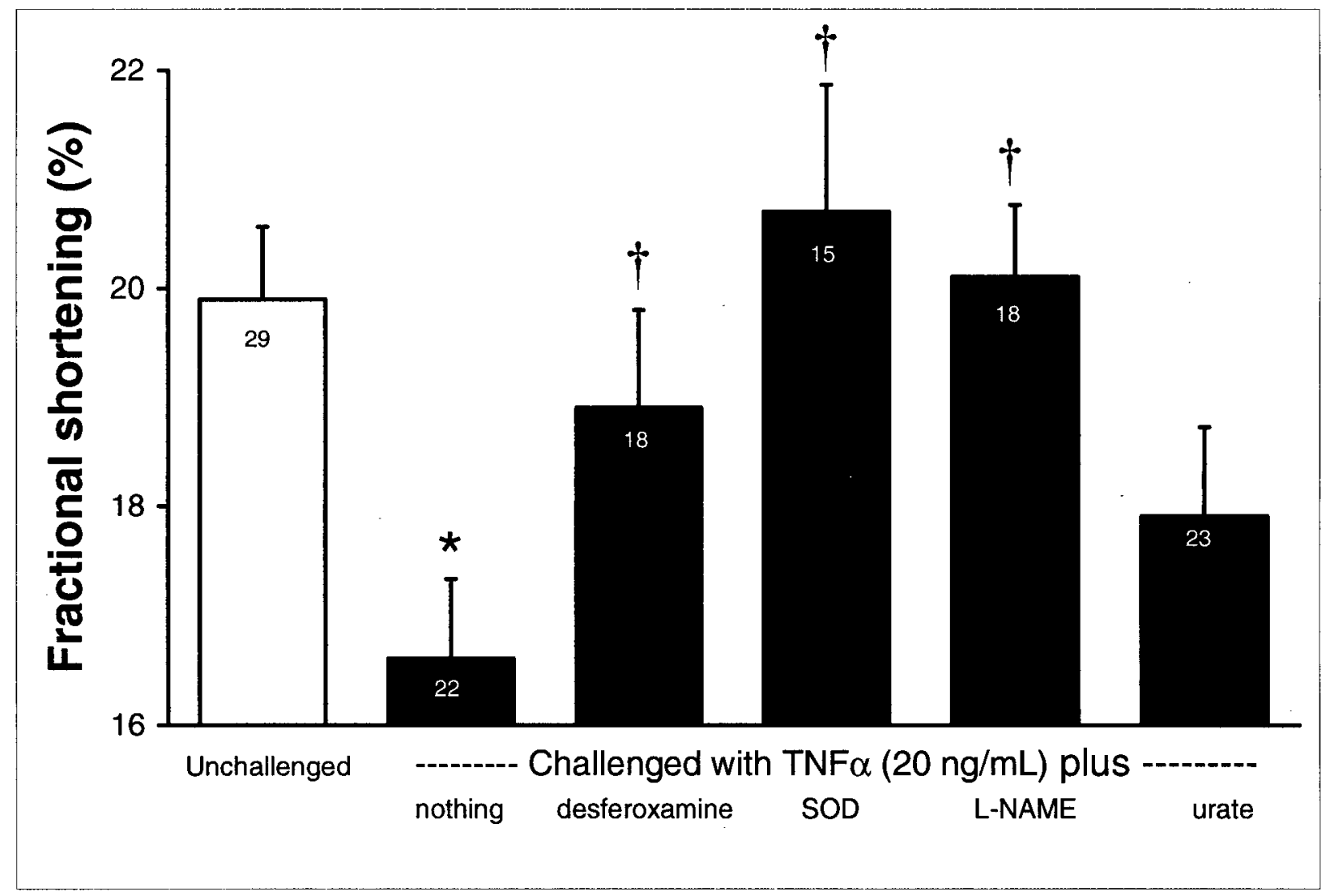

FIGURE 7-Fractional shortening of rat cardiac myocytes co-incubated with rat macrophages after 4 hour exposure to TNF $\alpha$. ( ${ }^{*}$ indicates $p<0.05$ compared to control and $t, \mathrm{n}$ is indicated on bars) 


\section{CHAPTER 4: DISCUSSION}

Taken together, these observations demonstrate that activated macrophages can contribute to cardiac myocyte contractile dysfunction. Adherence of activated macrophages to ICAM-1 expressed on activated cardiac myocytes appears to be an important step in mediating the observed contractile dysfunction. TNF $\alpha$, which has not only been clearly implicated as an important mediator in sepsis $(10,11)$, has been shown to induce the release of IL-1 $\beta$ from macrophages (10). This cytokine plays a role by contributing to macrophage activation and adhesion and, possibly, by mediating part of the effect of adherent macrophages. Both NO and oxygen free radicals seem to contribute to the myocardial depressant effect of adherent macrophages.

\subsection{Fractional Shortening}

An important characteristic of cardiovascular dysfunction in sepsis is the decrease in left ventricular contractility (8). By using myocyte fractional shortening as representative of contractility, our results extend previous findings by demonstrating that activated macrophages can contribute to myocardial dysfunction. In contrast, TNF $\alpha$ in the absence of macrophages did not decrease fractional shortening of cardiac myocytes. Lack of direct TNF $\alpha$ effects in our study differs from the initial observations of Finkel et al. (23) but agree with the observations of Kumar et al. who also found that TNF $\alpha$ and IL-1 $\beta$ separately do not decrease cardiac myocyte function. TNF $\alpha$ and IL-1 $\beta$, which are released during the body's immunological response to sepsis, may act synergistically to decrease contractility 
(43). It follows that one potential explanation for our results that macrophages decreased myocyte contractility because they release both TNF $\alpha$ and IL-1 $\beta$. However, if this were the only mechanism of macrophage effect then physical separation of macrophages and myocytes using culture well inserts should not have prevented the decrease in inflammatory mediator-induced myocyte contractility. Similarly, anti-ICAM-1, which simply prevented macrophage adhesion to cardiac myocytes, should not have prevented decreased myocyte contractility.

\subsection{Role of Macrophage Adherence on Myocyte Function}

Cytokine induction of ICAM-1 on cardiac myocytes have been observed as being a critical step in myocarditis (32). Macrophage binding to cardiac myocytes has been shown to involve ICAM-1. Our ELISAs showed this ICAM-1 expression on cardiac myocytes after TNF $\alpha$ challenge. This expression on cardiac myocytes has also been observed following TNF $\alpha$, IL-1 $\beta$, and monocyte chemotactic protein-1 (MCP-1) challenge (32). Adherence of macrophages to myocytes via ICAM-1 appears to be also important in macrophageinduced myocyte dysfunction. Smith et al. have shown that when exposed to either TNF $\alpha$, IL-1 $\beta$, or LPS, canine cardiac myocytes synthesize and express ICAM-1 on their membrane, which allows leukocytes to adhere while their adherence to myocytes can also be blocked by anti-ICAM-1 (33).

Adherence could contribute to decreased contractility in at least two ways. First, adherence may simply keep macrophages in very close proximity to cardiac myocytes so that 
mediator concentrations (for example, TNF $\alpha$ and IL-1 $\beta$, as well as oxygen free radicals and NO) are high in the immediate vicinity of the cardiac myocyte. In other tissues, leukocytes can adhere to cells, enveloping a pocket between the two cells that may contain very high concentrations of mediators. Thus, physical proximity may be an important issue. The second possibility is that cardiac myocyte ICAM-1 may act as a receptor that, by itself or in conjunction with co-stimuli, may result in intracellular signalling leading to decreased contractile function.

\subsection{Role of Oxygen Free Radicals and Nitric Oxide on Myocyte Function}

In addition to TNF $\alpha$ and other cytokines, oxygen free radicals and nitric oxide also seem to play important roles by mediating the contractile dysfunction induced by activated, adherent macrophages (23-29). This mediation of dysfunction was observed when the decrease in fractional shortening was inhibited following the co-incubation of the co-culture with nitric oxide and NO synthase inhibitors after TNF $\alpha$ challenge (Figure 7). Several studies support these findings by showing that part of the effect of pro-inflammatory cytokines in vitro is due to stimulation of nitric oxide production in cardiac myocytes $(23,27,45,46)$. There is growing evidence, as shown in isolated working hearts, that TNF $\alpha$ and IL-1 $\beta$ release contribute to the production of oxygen free radicals and NO. The production of oxygen free radicals and NO could then mediate part of their effect as components of intracellular signal transduction by combining to form peroxynitrites which could cause damage to cell membranes, thus contributing to decreased contractile function (47). Another possible pathway for NO in mediating contractile function is that production 
of NO stimulates the guanylate cyclase pathway within the cardiac myocytes, reducing intracellular calcium, which could, in turn, decreases cardiac contractility $(28,45,53-55)$.

It is important to recognize that we used macrophages that had emigrated from the blood to the peritoneal cavity. Emigrated leukocytes express different cell adhesion molecules than the circulating blood population (56). While peritoneal macrophages may differ from those recruited to the heart during an inflammatory response we felt that emigrated peritoneal macrophages may better model emigrated intramyocardial macrophages than peripheral blood monocytes.

In summary, activated macrophages adhering to cardiac myocytes via ICAM-1, after challenging with TNF $\alpha$, could contribute to myocardial contractile dysfunction through a decrease in myocyte fractional shortening. The effects of adherent macrophages are mediated in part by oxygen free radicals and nitric oxide.

\subsection{Further Studies}

Neutrophils and macrophages have been found to both bind via ICAM-1. Since these two cells are both present during the sepsis, further work could examine which cell binds with greater affinity when both macrophages and neutrophils are co-cultured with myocytes. 
$\mathrm{IL}-1 \beta$ and TNF $\alpha$ are present in the early stages of the septic inflammatory cascade. Other studies could also examine the cytokines which are triggered later on, such as IL-6.

ICAM-1 has been shown to be very important in macrophage-induced myocyte dysfunction. However, when anti-ICAM-1 was used, the effect of increased macrophage adhesion and decreased myocyte contractility was not completely blocked. By exploring other adhesion molecules, one might be in a better position to understand what other molecules besides ICAM-1 play a role in macrophage adhesion. 


\section{REFERENCES}

1. Vincent, J.L. 1994. Sepsis and septic shock: update on definitions. In Reinhart, K.,

K. Eyrich, C. Sprung, eds. Sepsis: Current perspectives in pathophysiology and therapy. Springer-Verlag.

2. Balk, R.A. and R.C. Bone. 1989. The septic syndrome. Crit. Care. Clin. 5(1):1-8.

3. Bone, R.C., R.A. Balk, A.M. Fein, T.M. Perl, R.P. Wenzel, H.D. Reines, R.W. Quenzer, T.J. Iberti, N.Macintyre, R.M.H. Schein, and the E5 Sepsis Study Group. 1995. A second large controlled clinical study of E5, a monoclonal antibody to endotoxin: Results of a prospective, multicenter, randomized, controlled trial. Crit. Care Med. 23 (6): 994-1005.

4. Cohn, I. Jr. and G.H. Bornside: Infections, in Schwartz S.I, G.T. Shires, F.C. Spenser (eds): Principles of Surgery, ed 5. New York, McGraw-Hill Book Co, 1989, pp 181215.

5. Ziegler, E.J., C.J. Fisher, C.L. Sprung, R.C. Straube, J.C. Sadoff, G.E. Foulke, C.H. Wortel, M.P. Find, R.P. Dellinger, N.T.H. Teng, I.E. Allen, H.J. Berger, G.L. Knatterud, A.R. LoBuglio, C.R. Smith, and HA-1A Sepsis Study Group. 1991. Treatment of gram-negative bacteremia and septic shock with HA-1A human monoclonal antibody against endotoxin. A randomized, double-blind, placebo-controlled trial. N. Engl. J. Med. 324: 429-436. 
6. Parker, M.M. and J.E. Parrillo. 1983. Septic shock: Hemodynamics and pathogenesis. JAMA. 250:3324.

7. MacLean, L.D., W.G. Mulligan, A.P.H. McLean, et al. 1967. Patterns of septic shock in man: A detailed study of 56 patients. Ann. Surg. 166:543-562.

8. Parrillo, J.E., C. Burch, J.H. Shelhamer, M.M. Parker, C. Natanson, and W. Schuette. 1985. A circulating myocardial depressant substance in humans with septic shock. Septic shock patients with a reduced ejection fraction have a circulating factor that depresses in vitro myocardial cell performance. J. Clin. Invest. 76: 1539-1553.

9. Reilly, J.M., R.E. Cunnion, C. Burch-Whitman, M.M. Parker, J.H. Shelhamer, and J.E. Parrillo. 1989. A circulating myocardial depressant substance is associated with cardiac dysfunction and peripheral hypoperfusion (lactic acidemia) in patients with septic shock. Chest. 95: 1072-1080.

10. Beutler, B. and A. Cerami. 1987. Cachectin: More than a tumor necrosis factor. N. Engl. J. Med. 316:379-385.

11. Tracey, K.J., B. Beutler, S.F. Lowry, et al. 1986. Shock and tissue injury induced by recombinant human cachectin. Science. 234:470-474. 
12. Tracey, K.J., and S.F. Lowry. 1990. The role of cytokine mediators in septic shock. Adv. Surg. 23: 21-56.

13. Bone, R.C. 1992. Toward an epidemiologic and natural history of SIRS (systemic inflammatory response syndrome). JAMA. 268:3452.

14. Johnston, R.B. 1988. Monocytes and macrophages. N. Engl. J. Med. 318: 747-752.

15. Slotman, G.J., K.W. Burchard, J.J. Williams, et al. 1986. Interaction of prostaglandins, activated complement, and granulocytes in clinical sepsis and hypotension. Surgery 99:744-750.

16. Birdsall, H.H., D.M. Green, J. Trial, K.A. Youker, A.R. Burns, C.R. MacKay, G.J. LaRosa, H.F. Hawkins, C.W. Smith, L.H. Michael, M.L. Entman, and R.D. Rossen. 1997. Complement $\mathrm{C} 5 \mathrm{a}$, TGF-beta 1 and MCP-1, in sequence, induce migration of monocytes into ischemic canine myocardium within the first one to five hours after reperfusion. Circulation 95: 684-692.

17. Gurevitch, J., I. Frolkis, Y. Yuhas, Y. Pas, M. Matsa, R. Mohr, and V. Yakirevich. 1996. Tumor necrosis factor-alpha is released from the isolated heart undergoing ischemia 
and reperfusion. J. Am. Coll. Cardiol. 28(1):247-252.

18. Ishiwata, T., F. Guo, Z. Naito, G. Asano, and R. Nishigaki. 1997. Differential distribution of ecNOS and iNOS mRNA in rat heart after endotoxin administration. Jap. Heart J. 38 (3): 445-455.

19. Bachmaier, K., N. Neu, C. Pummerer, G.S. Duncan, T.W. Mak, T. Matsuyama, and J.M. Penninger. 1997. iNOS expression and nitrotyrosine formation in the myocardium in response to inflammation is controlled by the interferon regulatory transcription factor 1 . Circulation. 96 (2): 585-591.

20. Robinson, N.M., K.R. Westmore, J.F. Martin, P. Emson, and I.G. Charles. 1997. Inducible nitric oxide synthase gene transcription and protein activity in the rat heart during endotoxaemia. Biochem. Biophys. Res. Commun. 231(1): 211-216.

21. Fyfe, A., P. Daly, L. Galligan, L. Pirc, C. Feindel, and C. Cardella. 1993. Coronary sinus sampling of cytokines after heart transplantation: evidence for macrophage activation and interleukin-4 production within the graft. J. Am. Coll. Cardiol. 21(1): 171-176.

22. Granton, J.T., C.M. Goddard, M.F. Allard, S. van Eeden, and K.R. Walley. 1997. Leukocytes and decreased left-ventricular contractility during endotoxemia in rabbits. Am. J. Respir. Crit. Care. Med. 155: 1977-1983. 
23. Finkel, M.S., C.V. Oddis, T.D. Jacob, S.C. Watkins, B.G. Hattler, and R.L. Simmons. 1992. Negative inotropic effects of cytokines on the heart mediated by nitric oxide. Science. 257: 387-389.

24. Eichenholz, P.W., P.Q. Eichacker, W.D. Hoffman, S.M. Banks, J.E. Parrillo, R.L. Danner, and C. Natanson. 1992. Tumor necrosis factor challenges in canines: patterns of cardiovascular dysfunction. Am. J. Physiol. 263: H668-H675.

25. Squadrito, F., D. Altavilla, B. Zingarelli, M. Ioculano, G. Calapai, G.M. Campo, A. Miceli, and A.P. Caputi. 1993. Tumor necrosis factor involvement in myocardial ischaemiareperfusion injury. Eur. J. Pharmacol. 237: 223-230.

26. Walley, K.R., P.C. Hebert, Y. Wakai, P.G. Wilcox, J.D. Road, and D.J. Cooper. 1994. Decrease in left ventricular contractility after tumor necrosis factor- $\alpha$ infusion in dogs. J. Appl. Physiol. 76: 1060-1067.

27. Brady, A.J., P.A. Poole-Wilson, S.E. Harding, and J.B. Warren. 1992. Nitric oxide production within cardiac myocytes reduces their contractility in endotoxemia. Am. J. Physiol. 263: H1963-H1966.

28. Schulz, R., D.L. Panas, R. Catena, S. Moncada, P.M. Olley, and G.D. Lopaschuk. 1995. The role of nitric oxide in cardiac depression induced by interleukin-1 $\beta$ and tumour 
necrosis factor- $\alpha$. Br. J. Pharmacol. 114: 27-34.

29. Herbertson, M.J., H.A. Werner, and K.R. Walley. 1996. Nitric oxide synthase inhibition partially prevents decreased LV contractility during endotoxemia. Am. J. Physiol. 270: H1979-H1984.

30. Beutler, B., I.W. Milsark, and A. Cerami. 1986. Passive immunization against cachectin/tumor necrosis factor protects mice from lethal effect of endotoxin. Science 234: 470-473.

31. Dinarello, C.A. 1984. Interleukin-1. Rev. Infect. Dis. 6: 55-95.

32. Ban, K., U. Ikeda, M. Takahashi, T. Kanbe, T. Kasahara, and K. Shimada. 1994. Expression of intercellular adhesion molecule-1 on rat cardiac myocytes by monocyte chemoattractant protein-1. Cardiovasc. Res. 28: 1258-1262.

33. Smith, C.W., M.L. Entman, C.L. Lane, A.L. Beaudet, T.I. Ty, K. Youker, H.K. Hawkins, and D.C. Anderson. 1991. Adherence of neutrophils to canine cardiac myocytes in vitro is dependent on intercellular adhesion molecule-1. J. Clin. Invest. 88: 1216-1223. 
34. Massey, K.D., R.M. Strieter, S.L. Kunkel, J.M. Danforth, and T.J. Standiford. 1995. Cardiac myocytes release leukocyte-stimulating factors. Am J Physiol. 269: H980-H987.

35. Entman, L., K. Youker, S.B. Shappell, C. Siegel, R. Rothlein, W.J. Dreyer, F.C. Schmaistieg, and C.W. Smith. 1990. Neutrophil adherence to isolated adult canine myocytes. Evidence for a CD18-dependent mechanism. J. Clin. Invest. 85: 1497-1506.

36. Hansen, P.R. and G. Stawski. 1994. Neutrophil mediated damage to isolated myocytes after anoxia and reoxygenation. Cardiovasc. Res. 28: 565-569.

37. Xie, Y.W., and M.S. Wolin. 1996. Role of nitric oxide and its interaction with superoxide in the suppression of cardiac muscle mitochondrial respiration. Involvement in response to hypoxia/reoxygenation. Circulation. 94: 2580-2586.

38. Parker M.M., J.H. Shelhamer, S.L. Bacharach,. M.V. Green, C. Natanson, T.M. Frederick, B.A. Damske, and J.E. Parrillo. 1984. Profound but reversible myocardial depression in patients with septic shock. Ann. Intern. Med. 100: 483-490.

39. Natanson, C. 1990. Studies using a canine model to investigate the cardiovascular abnormality of and potential therapies for septic shock. Clin. Res. 38: 206-214. 
40. Herbertson, M.J., H.A. Werner, J.A. Russell, K. Iversen, and K.R. Walley. 1995. Myocardial oxygen extraction ratio is decreased during endotoxemia in pigs. J. Appl. Physiol. 79: 479-486.

41. Goddard, C.M., M.F. Allard, J.C. Hogg, and K.R. Walley. 1996. Myocardial morphometric changes related to decreased contractility after endotoxin. Am. J. Physiol. 270: $\mathrm{H} 1446-\mathrm{H} 1452$.

42. Brigham, K.L., and B. Meyrick. 1986. Endotoxin and lung injury. Am. Rev. Respir. Dis. 133: $913-927$.

43. Kumar, A., V. Thota, L. Dee, J. Olson, E. Uretz, and J.E. Parrillo. 1996. Tumor necrosis factor alpha and interleukin 1beta are responsible for in vitro myocardial cell depression induced by human septic shock serum. J. Exp. Med. 183: 949-958.

44. Herbertson, M.J., H.A. Werner, C.M. Goddard, J.A. Russell, A. Wheeler, R. Coxon, and K.R. Walley. 1995. Anti-tumor necrosis factor-alpha prevents decreased ventricular contractility in endotoxemic pigs. Am. J. Respir. Crit. Care. Med. 152:480-8

45. Pinsky, D.J., B. Cai, X. Yang, C. Rodriguez, R.R. Sciacca, and R.J. Cannon. 1995. The lethal effects of cytokine-induced nitric oxide on cardiac myocytes are blocked by nitric oxide synthase antagonism or transforming growth factor beta. J. Clin. Invest. 95: 677-685. 
46. Ungureanu-Longrois, D., J.L. Balligand, W.W. Simmons, I. Okada, L. Kobzik, C.J. Lowenstein, S.L. Kunkel, T. Michel, R.A. Kelly, and T.W. Smith. 1995. Induction of nitric oxide synthase activity by cytokines in ventricular myocytes is necessary but not sufficient to decrease contractile responsiveness to beta-adrenergic agonists. Circ. Res. 77(3): 494502.

47. Yasmin, W., K.D. Strynadka, and R. Schulz. 1997. Generation of peroxynitrite contributes to ischemia-reperfusion injury in isolated rat hearts. Cardiovasc. Res. 33: 422432.

48. Gurevitch, J. I. Frolkis, Y. Yuhas, B. Lifschitz-Mercer, E Berger Y. Paz, M. Matsa, A. Kramer, and R. Mohr. 1997. Anti-tumor necrosis factor-alpha improves myocardial recovery after ischemia and reperfusion. J. Amer. Coll. Cardiol. 30: 1554-1561.

49. Herskowitz, A., S. Choi, A.A. Ansari, and S. Wesselingh. 1995. Cytokine mRNA expression in postischemic/reperfused myocardium. Am. J. Pathol. 146: 419-428.

50. loculano, M., D. Altavilla, F. Squadrito, P. Canale, G. Squadrito, A. Saitta, G.M. Campo, and A.P. Caputi. 1995. Tumour necrosis factor mediates E-selectin production and leukocyte accumulation in myocardial ischaemia-reperfusion injury. Pharmacol. Res. 31: $281-288$. 
51. Goddard, C.M., M.F. Allard, J.C. Hogg, M.J. Herbertson, and K.R. Walley. 1995. Prolonged leukocyte transit time in coronary microcirculation of endotoxemic pigs. Am J Physiol. 269: H1389-H1397.

52. Hiramatsu, T., J.M. Forbess, T. Miura, F. Nomura, and J.E. Mayer Jr. 1995. Additive effects of L-arginine infusion and leukocyte depletion on recovery after hypothermic ischemia in neonatal lamb hearts. J. Thorac. Cardiovasc. Surg. 110: 172-9

53. Xu, Y., M. Rojkind, and M.J. Czaja. 1996. Regulation of monocyte chemoattractant protein 1 by cytokines and oxygen free radicals in rat hepatic fat-storing cells. Gastroenterol. 110: 1870-1877.

54. Park, Y.C., S.J. Park, C.D. Jun, G.E. Kim, K. I. Park, H.D. Kim, R.K. Park, and H.T. Chung. 1997. Cyclic AMP analogue as a triggering signal for the induction of nitric oxide synthesis in murine peritoneal macrophages. Cell. Immunol. 179: 41-47.

55. Schroeder R.A., A. delaTorre, and P.C. Kuo. 1997. CD14-dependent mechanism for endotoxin-mediated nitric oxide synthesis in murine macrophages. Am. J. Physiol. 273: C1030-C1039.

56. Reinhardt, P.H., C.A. Ward, W.R. Giles, and P. Kubes. 1997. Emigrated rat neutrophils adhere to cardiac myocytes via alpha 4 integrin. Circ Res. 81: 196-201. 
57. Buttery, L.D.., T.J. Evans, D.R. Springall, A. Carpenter, J. Cohen, and J.M. Polak. 1994. Immunochemical localization of inducible nitric oxide synthase in endotoxin-treated rats. Lab. Invest. 71: 755-764.

58. Balligand, J.-L., D. Ungureanu-Longrois, W.W. Simmons, L. Kobzik, C.J. Lowenstein, S. Lamas, R.A. Kelly, T.W. Smith, and T. Michel. 1995. Induction of NO synthase in rat cardiac microvascular endothelial cells by IL-1 beta and IFN-gamma. Am. J. Physiol. 268: H1293-H1303.

59. Walker B.A., A.J. Seiler, C.A. Owens, B.E. Hagenlocker, and P.A. Ward. 1991. Absence of FMLP receptors on rat macrophages. J. Leuk. Biol. 50(6): 600-606. 
APPENDIX I: EXPERIMENTAL DATA

1a) Fractional shortening of myocytes co-incubated with antibodies, after no challenge.

\begin{tabular}{|c|c|c|c|c|c|c|c|c|}
\hline & \multicolumn{2}{|c|}{$\begin{array}{c}\text { No } \\
\text { macrophages }\end{array}$} & \multicolumn{2}{|c|}{ No Antibodies } & \multicolumn{2}{|c|}{ anti-ICAM-1 } & \multicolumn{2}{|c|}{ anti-TNFa } \\
\hline & cell & \%diff & Cell & \%diff & cell & \%diff & Cell & \%diff \\
\hline No & 1 & 30.73 & 1 & 19.11 & 1 & 23.76 & 1 & 13.58 \\
\hline Challenge & 2 & 19.81 & 2 & 20.57 & 2 & 16.97 & 2 & 23.08 \\
\hline & 3 & 17.28 & 3 & $27: 51$ & 3 & 21.71 & 3 & 16.1 \\
\hline & 4 & 23.7 & 4 & 28.49 & 4 & 14.56 & 4 & 15.78 \\
\hline & 5 & 21.39 & 5 & 28.21 & 5 & 23.16 & 5 & 7.98 \\
\hline & 6 & 17.24 & 6 & 15.08 & 6 & 26.2 & 6 & 18.65 \\
\hline & 7 & 18.89 & 7 & 15.56 & 7 & 26.89 & 7 & 24.3 \\
\hline & 8 & 24.29 & 8 & 16.49 & 8 & 9.25 & & \\
\hline & 9 & 21.61 & 9 & 14.8 & 9 & 20.85 & & \\
\hline & 10 & 30.07 & 10 & 22.34 & 10 & 24.76 & & \\
\hline & 11 & 26.19 & 11 & 16.46 & 11 & 20.02 & & \\
\hline & 12 & 21.69 & 12 & 20.44 & 12 & 14.51 & & \\
\hline & 13 & 29.33 & 13 & 13.62 & 13 & 21.25 & & \\
\hline & 14 & 19.44 & 14 & 19.15 & 14 & 22.04 & & \\
\hline & 15 & 21.02 & 15 & 22.92 & 15 & 18.02 & & \\
\hline & 16 & 23.65 & 16 & 25.96 & 16 & 16.07 & & \\
\hline & 17 & 21.79 & 17 & 18.61 & 17 & 23.73 & & \\
\hline & 18 & 21.15 & 18 & 23.25 & 18 & 17.14 & & \\
\hline & 19 & 22.91 & 19 & 16.47 & & & & \\
\hline & 20 & $\begin{array}{l}24.32 \\
? 194\end{array}$ & & & & & & \\
\hline Mean & & 22.78 & & 20.27 & & 20.05 & & 17.07 \\
\hline Std Err. & & 0.82 & & 1.09 & & 1.10 & & 2.12 \\
\hline
\end{tabular}


1b) Fractional shortening after TNF $\alpha$ challenge.

\begin{tabular}{|c|c|c|c|c|c|c|c|c|}
\hline & \multicolumn{2}{|c|}{ no macrophages } & \multicolumn{2}{|c|}{ no antibodies } & \multicolumn{2}{|c|}{ Anti-ICAM-1 } & \multicolumn{2}{|c|}{ anti-TNFa } \\
\hline & cell & $\%$ diff & cell & $\%$ diff & Cell & $\%$ diff & cell & $\%$ diff \\
\hline TNFa & 1 & 29.71 & 1 & 17.44 & 1 & 21.65 & 1 & 14.91 \\
\hline & 2 & 19.71 & 2 & 12.79 & 2 & 21.91 & 2 & 24 \\
\hline & 3 & 28.06 & 3 & 14.77 & 3 & 18.47 & 3 & 11.76 \\
\hline & 4 & 20.76 & 4 & 15.54 & 4 & 26.22 & 4 & 23.36 \\
\hline & 5 & 28.75 & 5 & 17.94 & 5 & 17.49 & 5 & 17.63 \\
\hline & 6 & 20.19 & 6 & 15.79 & 6 & 15.6 & 6 & 14.25 \\
\hline & 7 & 23.65 & 7 & 19.37 & 7 & 23.08 & 7 & 21.34 \\
\hline & 8 & 21.14 & 8 & 9.07 & 8 & 23.49 & 8 & 12.92 \\
\hline & 9 & 16.49 & 9 & 2.23 & 9 & 10.94 & 9 & 21.61 \\
\hline & 10 & 22.07 & 10 & 19.12 & 10 & 16.82 & 10 & 17.56 \\
\hline & 11 & 17.75 & 11 & 13.36 & 11 & 28.89 & 11 & 16 \\
\hline & & & 12 & 11.97 & 12 & 13.67 & 12 & 19.16 \\
\hline & & & 13 & 22.75 & 13 & 20.68 & 13 & 14.08 \\
\hline & & & 14 & 15.73 & 14 & 26.14 & 14 & 20.78 \\
\hline & & & 15 & 13.13 & 15 & 22.05 & 15 & 20.38 \\
\hline & & & 16 & 21.21 & 16 & 24.79 & & \\
\hline & & & 17 & 14.81 & 17 & & & \\
\hline & & & 18 & 19.12 & & & & \\
\hline Mean & & 22.57 & & $\overline{15.34}$ & & 20.74 & & 17.98 \\
\hline Std Err & & 1.35 & & 1.12 & & 1.23 & & 1.00 \\
\hline
\end{tabular}


1c) Fractional shortening after LPS challenge.

\begin{tabular}{|c|c|c|c|c|c|c|c|c|}
\hline & \multicolumn{2}{|c|}{ no macrophages } & \multicolumn{2}{|c|}{ no challenge } & \multicolumn{2}{|c|}{ anti-ICAM-1 } & \multicolumn{2}{|c|}{ anti-TNFa } \\
\hline & cell & \%diff & & \%diff & & $\%$ diff & cell & $\%$ diff \\
\hline LPS & 1 & 21.35 & 1 & 19.9 & 1 & 17.67 & 1 & 15.45 \\
\hline & 2 & 14.79 & 2 & 13.96 & 2 & 14.56 & 2 & 15.24 \\
\hline & 3 & 22.79 & 3 & 14.66 & 3 & 17.45 & 3 & 13.88 \\
\hline & 4 & 19.72 & 4 & 17.98 & 4 & 18.41 & 4 & 12.23 \\
\hline & 5 & 17.58 & 5 & 23.49 & 5 & 21 & 5 & 18.4 \\
\hline & 6 & 20.91 & 6 & 7.28 & 6 & 19.5 & 6 & 21.21 \\
\hline & 7 & 6.48 & 7 & 7.91 & & & 7 & 17.12 \\
\hline & 8 & 15.08 & 8 & 17.85 & & & 8 & 19.82 \\
\hline & 9 & 27.66 & 9 & 12.73 & & & 9 & 20.61 \\
\hline & 10 & 25.52 & & & & & 10 & 22.22 \\
\hline & 11 & 19.13 & & & & & 11 & 19.36 \\
\hline & 12 & 26.29 & & & & & 12 & 23.28 \\
\hline & 13 & 18.44 & & & & & & \\
\hline & 14 & 15.55 & & & & & & \\
\hline & 15 & 22.62 & & & & & & \\
\hline & 16 & 18.57 & & & & & & \\
\hline & 17 & 18.26 & & & & & & \\
\hline & 18 & 19.38 & & & & & & \\
\hline & 19 & 18.18 & & & & & & \\
\hline & 20 & 6.06 & & & & & & \\
\hline & 21 & 7.83 & & & & & & \\
\hline & 22 & 24.1 & & & & & & \\
\hline & 23 & 12.25 & & & & & & \\
\hline & 24 & 23.53 & & & & & & \\
\hline & 25 & 23.19 & & & & & & \\
\hline & 26 & 24.83 & & & & & & \\
\hline & 27 & 21.21 & & & & & & \\
\hline & 28 & 20.89 & & & & & & \\
\hline & 29 & 20.05 & & & & & & \\
\hline & 30 & 36.55 & & & & & & \\
\hline & 31 & 24.36 & & & & & & \\
\hline & 32 & 19.93 & & & & & & \\
\hline & 33 & 17.87 & & & & & & \\
\hline & 34 & 16.87 & & & & & & \\
\hline & 35 & 18.64 & & & & & & \\
\hline & 36 & 14.3 & & & & & & \\
\hline & 37 & 22.19 & & & & & & \\
\hline Mean & & 19.54 & & 15.08 & & 18.10 & & 18.24 \\
\hline Std Err & & 0.96 & & 1.78 & & 0.89 & & 1.00 \\
\hline
\end{tabular}


2) Macrophage adherence to cardiac myocytes after 3 and 4 hours of challenge.

\begin{tabular}{|c|c|c|c|}
\hline & hours & & ours \\
\hline unchallenged & TNF $\alpha$ challenge & unchallenged & TNF $\alpha$ challenge \\
\hline 3 & 4 & 3 & 3 \\
\hline 4 & 7 & 2 & 6 \\
\hline 1 & 3 & 3 & 5 \\
\hline 6 & 5 & 4 & 5 \\
\hline 2 & 1 & 2 & 3 \\
\hline 1 & 5 & 1 & 4 \\
\hline 0 & 2 & 1 & 2 \\
\hline 3 & 1 & 5 & 5 \\
\hline 0 & 5 & 4 & 1 \\
\hline 0 & 2 & 4 & 2 \\
\hline 2 & 4 & 1 & 8 \\
\hline 4 & 3 & 4 & 5 \\
\hline 0 & 6 & 0 & 2 \\
\hline 3 & 1 & 2 & 5 \\
\hline 1 & 5 & 1 & 5 \\
\hline 1 & 1 & 3 & 3 \\
\hline 0 & 3 & 1 & 5 \\
\hline 1 & 2 & 6 & 2 \\
\hline 4 & 3 & 4 & 3 \\
\hline 0 & 5 & 3 & 5 \\
\hline 1 & 1 & 4 & 6 \\
\hline 2 & 2 & 1 & 5 \\
\hline 0 & 6 & 3 & 8 \\
\hline 0 & 4 & 2 & 2 \\
\hline 2 & 1 & 0 & 5 \\
\hline 2 & 0 & 3 & 7 \\
\hline 0 & 3 & 2 & 4 \\
\hline 0 & 5 & 5 & 5 \\
\hline 0 & 5 & 0 & 0 \\
\hline 2 & 7 & 3 & 3 \\
\hline 0 & 2 & 4 & 4 \\
\hline 1 & 5 & 2 & 4 \\
\hline 0 & 4 & 2 & 6 \\
\hline 2 & 9 & 5 & 4 \\
\hline 3 & 3 & 5 & 3 \\
\hline 4 & 4 & 2 & 5 \\
\hline 2 & 1 & 1 & 4 \\
\hline 0 & 4 & 2 & 8 \\
\hline 3 & 2 & 4 & 0 \\
\hline
\end{tabular}




\begin{tabular}{|c|cc|cc|}
\hline & \multicolumn{2}{|c|}{3 hours (cont'd) } & \multicolumn{2}{c|}{ 4 hours (cont'd) } \\
\hline & Unchallenged & TNF $\alpha$ chall & Unchallenged & TNF $\alpha$ challenged \\
\hline & 5 & 4 & 0 & 2 \\
& 6 & 5 & 3 & 9 \\
& 2 & 6 & 2 & 4 \\
& 0 & 2 & 1 & \\
& 3 & 8 & 2 & \\
& 4 & 3 & 4 & \\
& 3 & & 3 & \\
& 0 & & 5 & \\
& 0 & & 2 & 0.19 \\
\hline mean & 5 & & 2.59 & \\
\hline Std Err & 1.78 & 3.64 & 0.32 & \\
\hline
\end{tabular}


3) ICAM Expression data from ELISA.

\begin{tabular}{|c|c|c|c|c|}
\hline Dose of TNF (ng/mL) & 0 & 10 & 20 & 50 \\
\hline Optical Density & 0.185 & 0.197 & 0.185 & 0.136 \\
& 0.187 & 0.242 & 0.217 & 0.085 \\
& 0.194 & 0.260 & 0.254 & 0.112 \\
& 0.268 & 0.315 & 0.312 & 0.462 \\
& 0.209 & 0.203 & 0.207 & 0.492 \\
& 0.198 & 0.226 & 0.181 & 0.291 \\
& 0.216 & 0.193 & 0.252 & 0.163 \\
& 0.240 & 0.297 & 0.309 & 0.255 \\
& 0.191 & 0.186 & 0.216 & \\
& 0.200 & 0.176 & 0.272 & \\
& 0.208 & 0.208 & 0.236 & \\
& 0.276 & 0.251 & 0.390 & \\
\hline Standard Error & 0.0089 & 0.013 & 0.018 & 0.055 \\
\hline
\end{tabular}


4) Fractional shortening of myocytes co-incubated with oxygen free radical scavengers, NO synthase inhibitors and peroxynitrite inhibitors.

\begin{tabular}{|c|c|c|c|c|c|c|c|c|c|c|}
\hline Cell \# & $\begin{array}{l}\text { No } \\
\text { chall }\end{array}$ & chall & $\begin{array}{l}\text { nchall } \\
\text { desfer }\end{array}$ & desferox & \begin{tabular}{|l} 
Nchall \\
SOD
\end{tabular} & SOD & $\begin{array}{l}\text { nchall } \\
\text { L-NAME }\end{array}$ & L-NAME & $\begin{array}{l}\text { nchall } \\
\text { urate }\end{array}$ & urate \\
\hline 1 & 22.63 & 15.33 & 12.93 & 21.83 & 20.62 & 21.91 & 16.9 & 16.1 & 25.41 & 15.15 \\
\hline 2 & 21.7 & 16.77 & 17.56 & 15.25 & 18.19 & 24.62 & 17.87 & 19.68 & 18.77 & 17.06 \\
\hline 3 & 22.84 & 16.33 & 18.49 & 15.36 & 21.58 & 18.8 & 14.97 & 16.24 & 18.4 & 5.18 \\
\hline 4 & 20.37 & 16.3 & 20.38 & 19.23 & 18.43 & 23.37 & 23.35 & 20.79 & 11.57 & 23.99 \\
\hline 5 & 16.2 & 15.87 & 16.03 & 24.34 & 21.45 & 10.44 & 17.89 & 22.56 & 20 & 16.19 \\
\hline 6 & 16.84 & 12.21 & 33.04 & 25.84 & 22.87 & 22.06 & 12.25 & 18.28 & 18.31 & 19.1 \\
\hline 7 & 18.71 & 7.79 & 23.32 & 14.32 & 22.24 & 18.26 & 13.39 & 20.76 & 18.24 & 20.3 \\
\hline 8 & 19.56 & 15.53 & 24.81 & 16.78 & 23.14 & 20.99 & 15.85 & 19.57 & 15.54 & 16.02 \\
\hline 9 & 17.72 & 16.22 & 18.95 & 21.17 & 20.02 & 23.79 & 19.68 & 22.71 & 22.39 & 21.56 \\
\hline 10 & 23.3 & 20.46 & 13.9 & 18.33 & 6.53 & 20.25 & 15.14 & 19.03 & 21.59 & 20.31 \\
\hline 11 & 13.23 & 10.43 & 9.94 & 20.42 & 21.56 & 29.27 & 19.35 & 17.72 & 12.35 & 15.31 \\
\hline 12 & 19.53 & 17.49 & 26.9 & 22.1 & 18.15 & 17.1 & 17.71 & 17.01 & 14.54 & 15.4 \\
\hline 13 & 21.91 & 24.35 & 17.4 & 20.3 & 19.96 & 20.75 & 13.92 & 19.02 & 17.8 & 14.86 \\
\hline 14 & 21.19 & 19.37 & 16.67 & 10.54 & 20.94 & 24.59 & 17.07 & 22.26 & 23.01 & 20.43 \\
\hline 15 & 15.16 & 15.21 & 14.53 & 16.27 & 20.31 & 15 & 15.48 & 17.06 & 16.64 & 17.62 \\
\hline 16 & 21.61 & 17.05 & 15.05 & 17.02 & & & 23.13 & 23.81 & 18.68 & 14.87 \\
\hline 17 & 11.82 & 18.41 & 15.91 & 19.01 & & & 16.78 & 19.06 & 13.58 & 24.31 \\
\hline 18 & 19.59 & 19.97 & 18.57 & 22.12 & & & 17.85 & 25.73 & 20.4 & 20.1 \\
\hline 19 & 22.6 & 16.91 & 23.72 & & & & 21.2 & 23.83 & 22.45 & 21 \\
\hline 20 & 14.7 & 17.86 & 20.87 & & & & 15.07 & & 16.89 & 17.02 \\
\hline 21 & 20.92 & 17.26 & 19.49 & & & & 14.35 & & 20.68 & 17.9 \\
\hline 22 & 19.64 & 18.54 & 27.82 & & & & 20.94 & & 16 & 20.08 \\
\hline 23 & 18.7 & & 16.23 & & & & 14.74 & & 16.34 & 17.71 \\
\hline 24 & 21.5 & & 20.62 & & & & 17.96 & & 19 & \\
\hline 25 & 28.57 & & & & & & 23.87 & & 28.79 & \\
\hline 26 & 24.32 & & & & & & & & & \\
\hline 27 & 18.68 & & & & & & & & & \\
\hline 28 & 23.67 & & & & & & & & & \\
\hline 29 & 19.77 & & & & & & & & & \\
\hline mean & 19.90 & 16.62 & 19.30 & 18.90 & 19.73 & 20.75 & 17.47 & 20.06 & 18.69 & 17.89 \\
\hline St Err & 0.66 & 0.73 & 1.07 & 0.90 & 1.03 & 1.16 & 0.63 & 0.66 & 0.79 & 0.82 \\
\hline
\end{tabular}


5) Mean macrophage adherences after co-incubation with oxygen free radical scavengers, peroxynitrite inhibitors, NO synthase inhibitors.

\begin{tabular}{|c|c|c|c|c|c|c|c|c|c|c|}
\hline Cell \# & $\begin{array}{c}\text { No } \\
\text { chall }\end{array}$ & chall & $\begin{array}{c}\text { No chall } \\
\text { desferox }\end{array}$ & $\begin{array}{c}\text { desfer } \\
\text { ox }\end{array}$ & $\begin{array}{c}\text { No chall } \\
\text { SOD }\end{array}$ & $\begin{array}{l}\text { SOD } \\
\text { No chall } \\
\text { L-NAME }\end{array}$ & $\begin{array}{c}\text { L- } \\
\text { NAME }\end{array}$ & $\begin{array}{c}\text { nchall } \\
\text { urate }\end{array}$ & urate \\
\hline 1 & 3 & 1 & 2 & 3 & 3 & 3 & 2 & 2 & 2 & 2 \\
2 & 2 & 2 & 4 & 1 & 3 & 2 & 2 & 1 & 1 & 2 \\
3 & 2 & 2 & 6 & 1 & 0 & 4 & 3 & 4 & 1 & 4 \\
4 & 2 & 2 & 6 & 1 & 2 & 2 & 1 & 2 & 1 & 4 \\
5 & 1 & 3 & 2 & 3 & 4 & 2 & 1 & 1 & 1 & 1 \\
6 & 3 & 5 & 5 & 1 & 3 & 1 & 2 & 4 & 2 & 2 \\
7 & 2 & 2 & 0 & 2 & 1 & 2 & 1 & 5 & 2 & 3 \\
8 & 3 & 1 & 3 & 4 & 4 & 2 & 2 & 0 & 0 & 2 \\
9 & 3 & 4 & 6 & 3 & 3 & 2 & 2 & 3 & 3 & 3 \\
10 & 5 & 3 & 6 & 0 & 4 & 4 & 4 & 1 & 4 & 2 \\
11 & 3 & 4 & 2 & 4 & 4 & 6 & 2 & 6 & 4 & 2 \\
12 & 3 & 3 & 2 & 3 & 5 & 3 & 2 & 3 & 2 & 2 \\
13 & 3 & 0 & 2 & 2 & 5 & 2 & 3 & 2 & 0 & 3 \\
14 & 4 & 1 & 1 & 4 & 6 & 3 & 1 & 3 & 5 & 1 \\
15 & 5 & 4 & 5 & 3 & 4 & 5 & 2 & 3 & 3 & 0 \\
16 & 4 & 3 & 7 & 3 & 5 & 2 & 1 & 1 & 0 & 1 \\
17 & 4 & 4 & 3 & 2 & 3 & 5 & 3 & 3 & 4 & 0 \\
18 & 5 & 2 & 3 & 4 & & 2 & 4 & 2 & 2 & 2 \\
19 & 2 & 2 & 2 & & & 4 & 1 & 2 & 4 & 1 \\
20 & 3 & 3 & 3 & & & 1 & 3 & 1 & 3 & 3 \\
21 & 3 & 3 & 4 & & & 3 & 1 & 3 & 1 & 1 \\
22 & 4 & 0 & 1 & & & 5 & 0 & & 3 & \\
23 & 2 & & 4 & & & & 2 & & 2 & \\
24 & 3 & & 3 & & & & 2 & & 1 & \\
25 & & & 5 & & & & 1 & & & \\
26 & & & 4 & & & & & & & \\
27 & & & 5 & & & & & & & \\
28 & & & & & & & & & & \\
29 & & & & & & & & & \\
\hline mean & 3.08 & 2.45 & 3.56 & 2.44 & 3.47 & 2.95 & 1.92 & 2.48 & 2.13 & 1.95 \\
\hline Sd Err & 0.22 & 0.29 & 0.35 & 0.29 & 0.37 & 0.30 & 0.20 & 0.32 & 0.29 & 0.24 \\
& & & & & & & & & & \\
\hline
\end{tabular}


6) Relationship between adherent macrophages and fractional shortening.

\begin{tabular}{|c|c|c|c|c|c|}
\hline \#macrophages & 2 & 3 & 4 & 5 & 6 \\
\hline & $\begin{array}{c}17.44 \\
12.79 \\
15.54 \\
17.94 \\
15.79 \\
9.07 \\
19.15 \\
17.44 \\
12.79 \\
17.98 \\
23.49 \\
15.54 \\
17.94 \\
15.79 \\
9.07 \\
17.98 \\
23.49 \\
24.76 \\
18.47 \\
26.22 \\
23.08 \\
16.82 \\
22.05 \\
24.79 \\
21 \\
16.1 \\
15.78 \\
24.3 \\
21.34 \\
16 \\
20.78 \\
15.24 \\
21.21 \\
23.28\end{array}$ & $\begin{array}{c}19.11 \\
20.57 \\
14.77 \\
28.49 \\
2.23 \\
19.12 \\
22.75 \\
22.34 \\
14.77 \\
17.85 \\
2.23 \\
19.12 \\
22.75 \\
17.85 \\
21.71 \\
14.56 \\
20.85 \\
21.65 \\
21.91 \\
15.6 \\
13.58 \\
7.98 \\
24 \\
14.25 \\
12.92 \\
17.56 \\
19.16 \\
18.4 \\
19.82 \\
20.61 \\
22.22\end{array}$ & $\begin{array}{c}27.51 \\
28.21 \\
15.08 \\
13.36 \\
15.73 \\
14.8 \\
22.92 \\
19.9 \\
7.28 \\
13.36 \\
15.73 \\
19.9 \\
7.28 \\
26.2 \\
17.14 \\
17.49 \\
23.49 \\
28.89 \\
17.67 \\
17.45 \\
23.08 \\
18.65 \\
23.36 \\
17.63 \\
20.38 \\
19.36\end{array}$ & $\begin{array}{c}16.46 \\
20.44 \\
25.96 \\
16.47 \\
13.96 \\
12.73 \\
13.96 \\
12.73 \\
20.02 \\
16.07 \\
10.94 \\
20.68 \\
18.41 \\
19.5 \\
21.61 \\
17.12\end{array}$ & $\begin{array}{c}15.56 \\
11.97 \\
13.13 \\
19.12 \\
18.61 \\
14.66 \\
7.91 \\
11.97 \\
13.13 \\
19.12 \\
14.66 \\
7.91 \\
23.76 \\
26.89 \\
14.56 \\
11.76 \\
13.88\end{array}$ \\
\hline Mean & 18.54 & 17.77 & 18.92 & 17.32 & 15.21 \\
\hline Std Error & 0.74 & 1.03 & 1.10 & 0.99 & 1.22 \\
\hline
\end{tabular}


7) Diastolic lengths of cardiac myocytes after TNF $\alpha$ and LPS challenge.

\begin{tabular}{|c|c|c|c|}
\hline & no challenge & TNF $\alpha$ challenge & LPS challenge \\
\hline lengths & 77 & 67 & 75 \\
& 65 & 61 & 48 \\
& 74 & 55 & 79 \\
& 69 & 61 & 71 \\
& 55 & 65 & 62 \\
& 79 & 79 & 84 \\
& 63 & 51 & 73 \\
& 63 & 55 & 68 \\
& 74 & 45 & 59 \\
& 74 & 67 & 75 \\
& 83 & 56 & 67 \\
& 60 & 64 & \\
& 68 & 62 & \\
& 71 & 56 & \\
& 63 & 82 & \\
& 69 & 75 & \\
& 72 & 71 & \\
& 66 & 52 & \\
& 58 & & \\
\hline Mean & 67 & & \\
\hline Std Err & 55 & & \\
& 62 & & \\
\hline
\end{tabular}


8) Myocytes incubated with macrophages after addition of well inserts.

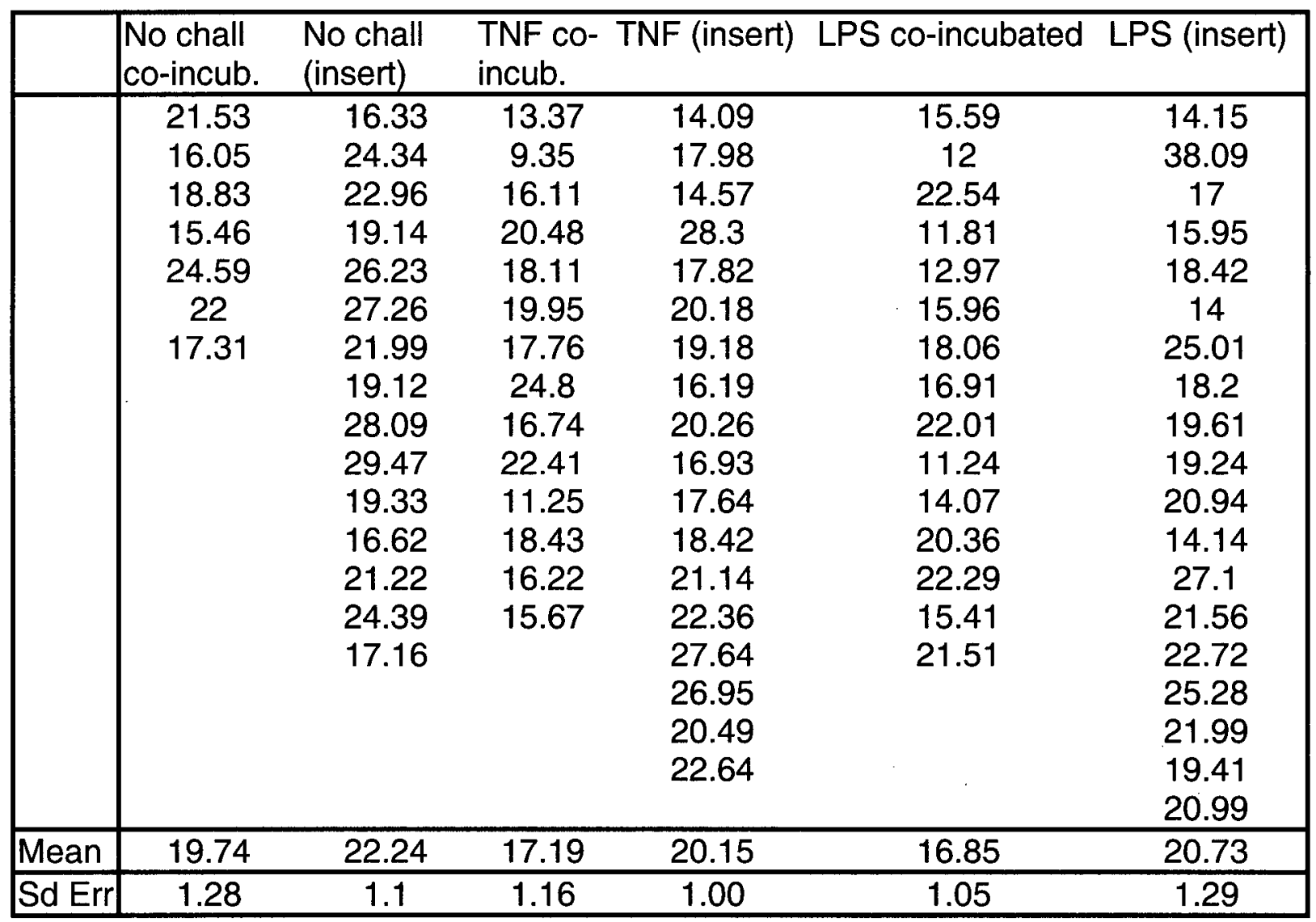


9) Mean macrophage adherences after co-incubation with antibodies and challenge.

\begin{tabular}{|c|c|c|c|c|c|c|c|c|c|c|c|}
\hline \multicolumn{4}{|c|}{ No antibody } & \multicolumn{4}{|c|}{ Anti-ICAM-1 } & \multicolumn{4}{|c|}{ anti-TNF } \\
\hline No Stim & TNF & IL-1 & LPS & No Stim & TNF & IL-1 & LPS & No Stim & TNF & IL-1 & LPS \\
\hline 3 & 4 & 2 & 3 & 4 & 1 & 7 & 1 & 4 & 1 & 0 & 3 \\
\hline 3 & 1 & 1 & 3 & 0 & 6 & 6 & 3 & 2 & 1 & 2 & 5 \\
\hline 6 & 0 & 1 & 2 & 1 & 0 & 2 & 5 & 3 & 0 & 0 & 0 \\
\hline 3 & 3 & 5 & 5 & 0 & 6 & 1 & 5 & 3 & 2 & 0 & 5 \\
\hline 0 & 1 & 2 & 5 & 2 & 1 & 0 & 3 & 1 & 1 & 0 & 5 \\
\hline 4 & 1 & 8 & 3 & 3 & 1 & 2 & 3 & 1 & 6 & 1 & 2 \\
\hline 3 & 2 & 4 & 5 & 3 & 4 & 1 & 2 & 0 & 5 & 1 & 1 \\
\hline 3 & 4 & 4 & 3 & 1 & 0 & 2 & 1 & 2 & 2 & 0 & 1 \\
\hline 3 & 6 & 1 & 2 & 2 & 3 & 7 & 1 & 0 & 4 & 2 & 1 \\
\hline 3 & 4 & 3 & 5 & 1 & 4 & 2 & 4 & 0 & 1 & 5 & 2 \\
\hline 1 & 6 & 5 & 5 & 2 & 2 & 6 & 2 & 3 & 1 & 3 & 3 \\
\hline 2 & 4 & 5 & 6 & 3 & 4 & 4 & 2 & 1 & 3 & 3 & 3 \\
\hline 3 & 3 & 3 & 4 & 2 & 4 & 3 & 0 & 2 & 2 & 0 & 3 \\
\hline 0 & 7 & 5 & 0 & 4 & 5 & 1 & 2 & 2 & 5 & 5 & 1 \\
\hline 3 & 2 & 9 & 2 & 0 & 5 & 0 & 5 & 1 & 6 & 5 & 4 \\
\hline 1 & 6 & 5 & 1 & 2 & 0 & 3 & 3 & 1 & 4 & 1 & 1 \\
\hline 2 & 3 & 1 & 0 & 3 & 4 & 0 & 4 & 1 & 3 & 3 & 3 \\
\hline 2 & 4 & 10 & 2 & 2 & 4 & 2 & 3 & 1 & 0 & 1 & 2 \\
\hline 2 & 3 & 2 & 4 & 1 & 3 & 1 & 2 & 1 & 5 & 3 & 0 \\
\hline 3 & 3 & 6 & 2 & 2 & 0 & 2 & 2 & 3 & 3 & 6 & 1 \\
\hline 3 & 5 & 4 & 2 & 3 & 2 & 1 & 1 & 3 & 1 & 0 & 0 \\
\hline 1 & 7 & 5 & 5 & 1 & 0 & 2 & 0 & 2 & 1 & 1 & 1 \\
\hline 3 & 1 & 8 & 9 & 1 & 1 & 3 & 1 & 0 & 4 & 1 & 3 \\
\hline 4 & 4 & 11 & 2 & 3 & 4 & 0 & 2 & 4 & 3 & 3 & 0 \\
\hline 2 & 4 & 4 & 1 & 2 & 2 & 4 & 0 & 1 & 5 & 3 & 0 \\
\hline 0 & 3 & 1 & 2 & 3 & 1 & 3 & 1 & 1 & 2 & 1 & 0 \\
\hline 2 & 7 & 3 & 3 & 1 & 0 & 2 & 3 & 3 & 4 & 2 & 0 \\
\hline 1 & 9 & 3 & 2 & 0 & 1 & 3 & 1 & 2 & 2 & 2 & 0 \\
\hline 1 & 4 & 5 & 4 & 0 & 2 & 2 & 2 & 2 & 4 & 2 & 1 \\
\hline 3 & 5 & 3 & 2 & 4 & 4 & 1 & 2 & 2 & 0 & 2 & 1 \\
\hline 2 & 1 & 4 & 2 & 2 & 2 & 2 & 5 & 3 & 3 & 2 & 0 \\
\hline 2 & 5 & 4 & 5 & 3 & 6 & 2 & 3 & 0 & 3 & 2 & 0 \\
\hline 3 & 7 & 3 & 2 & 4 & 4 & 1 & 0 & 3 & 0 & 7 & 2 \\
\hline 1 & 4 & 1 & 5 & 3 & 3 & 2 & 2 & 2 & 2 & 3 & 2 \\
\hline 2 & 6 & 3 & 2 & 1 & 1 & 5 & 1 & 5 & 1 & 2 & 2 \\
\hline 3 & 3 & 4 & 1 & 3 & 1 & 1 & 2 & 2 & 3 & 4 & 1 \\
\hline 3 & 2 & 4 & 4 & 0 & 0 & 2 & 1 & 3 & 1 & 3 & 1 \\
\hline 3 & 5 & 2 & 6 & 4 & 1 & 3 & 0 & 1 & 1 & 2 & 2 \\
\hline 2 & 2 & 3 & 3 & 1 & 0 & 5 & 0 & 1 & 0 & 3 & 1 \\
\hline 3 & 2 & 3 & 1 & 2 & 1 & 1 & 4 & 0 & 1 & 3 & 2 \\
\hline 4 & 5 & 1 & 3 & 2 & 2 & 0 & 2 & 1 & 3 & 3 & 3 \\
\hline 1 & 4 & 5 & 7 & 1 & 3 & 3 & 4 & 5 & 2 & 2 & 3 \\
\hline 2 & 3 & 6 & 5 & 3 & 4 & 5 & 1 & 4 & 2 & 1 & 0 \\
\hline 0 & 4 & 1 & 5 & 3 & 1 & 1 & 3 & 2 & 0 & 4 & 1 \\
\hline 2 & 6 & 2 & 3 & 5 & 4 & 3 & 2 & 1 & 4 & 5 & 3 \\
\hline 2 & 5 & 3 & 2 & 3 & 0 & 3 & 0 & 5 & 3 & 2 & 2 \\
\hline 0 & 3 & 1 & 2 & 1 & 0 & 1 & 3 & 1 & 1 & 4 & 1 \\
\hline 0 & 4 & 4 & 3 & 3 & 3 & 3 & 2 & 2 & 3 & 3 & 1 \\
\hline
\end{tabular}




\begin{tabular}{|c|c|c|c|c|c|c|c|c|c|c|c|}
\hline \multicolumn{4}{|c|}{ No antibody (cont'd) } & \multicolumn{4}{|c|}{ Anti-ICAM-1 (cont'd) } & \multicolumn{4}{|c|}{ Anti-TNF (cont'd) } \\
\hline No chall & TNF & $\mathrm{IL}-1$ & LPS & No chall & TNF & $\mid \mathrm{L}-1$ & LPS & No chall & TNF & IL-1 & LPS \\
\hline 1 & 4 & 3 & 1 & 1 & 2 & 2 & 1 & 2 & 3 & 2 & 1 \\
\hline 1 & 2 & 2 & 2 & 2 & 3 & 2 & 2 & 1 & 2 & 4 & 1 \\
\hline 5 & 3 & 7 & 3 & 3 & 3 & 2 & 3 & 2 & 2 & 2 & 2 \\
\hline 5 & 3 & 3 & 1 & 0 & 3 & 4 & 1 & 5 & 2 & 1 & 0 \\
\hline 6 & 2 & 3 & 3 & 0 & 2 & 4 & 1 & 1 & 0 & 2 & 0 \\
\hline 9 & 0 & 0 & 2 & 1 & 1 & 4 & 1 & 0 & 1 & 0 & 2 \\
\hline 0 & 0 & 3 & 0 & 2 & 1 & 5 & 0 & 3 & 1 & 3 & 1 \\
\hline 0 & 1 & 4 & 1 & 3 & 1 & 2 & 0 & 3 & 3 & 1 & 0 \\
\hline 1 & 3 & 3 & 3 & 1 & 2 & 3 & 2 & 1 & 1 & 0 & 1 \\
\hline 2 & 2 & 1 & 1 & 2 & 3 & 0 & 2 & 0 & 1 & 1 & 1 \\
\hline 3 & 3 & 2 & 1 & 2 & 0 & 1 & 1 & 0 & 2 & 0 & 1 \\
\hline 2 & 2 & 0 & 2 & 4 & 0 & 0 & 1 & 2 & 1 & 0 & 2 \\
\hline 2 & 2 & 1 & 2 & 2 & 1 & 1 & 1 & 2 & 0 & 2 & 0 \\
\hline 0 & 4 & 2 & 2 & 3 & 0 & 2 & 0 & 3 & 1 & 1 & 1 \\
\hline 1 & 1 & 2 & 2 & 3 & 2 & 1 & 1 & 1 & 4 & 1 & 1 \\
\hline 0 & 1 & 3 & 1 & 0 & 3 & 3 & 3 & 3 & 4 & 3 & 1 \\
\hline 2 & 1 & 2 & 4 & 2 & 0 & 2 & 0 & 2 & 1 & 1 & 0 \\
\hline 0 & 2 & 3 & 2 & 1 & 2 & 2 & 0 & 1 & 1 & 2 & 0 \\
\hline 1 & 3 & 7 & 2 & 1 & 1 & 5 & 1 & 2 & 1 & 1 & 1 \\
\hline 2 & 1 & 1 & 0 & 1 & 1 & 1 & 0 & 2 & 1 & 1 & 0 \\
\hline 2 & 0 & 0 & 1 & 0 & 0 & 2 & 1 & 1 & 0 & 4 & 4 \\
\hline 2 & 2 & 1 & 1 & 1 & 2 & 1 & 2 & 0 & 2 & 1 & 1 \\
\hline 2 & 2 & 2 & 3 & 1 & 1 & 1 & 0 & 1 & 2 & 0 & 1 \\
\hline 1 & 4 & 5 & 1 & 0 & 2 & 2 & 1 & 0 & 1 & 3 & 0 \\
\hline 1 & 5 & 3 & 3 & 1 & 4 & 0 & 2 & 1 & 1 & 1 & 1 \\
\hline 1 & 3 & 0 & 4 & 0 & 0 & 3 & 1 & 1 & 0 & 0 & 4 \\
\hline 3 & 3 & 1 & 1 & 0 & 1 & 1 & 2 & 0 & 1 & 0 & 2 \\
\hline 1 & 1 & 1 & 1 & 3 & 0 & 3 & 0 & 2 & 0 & 1 & 2 \\
\hline 1 & 0 & 2 & 3 & 1 & 1 & 1 & 4 & 0 & 1 & 2 & 0 \\
\hline 2 & 4 & 3 & 0 & 4 & 1 & 2 & 2 & 2 & 4 & 0 & 2 \\
\hline 2 & 3 & 3 & 4 & 1 & 0 & 1 & 0 & 2 & 3 & 3 & 2 \\
\hline 1 & 2 & 3 & 2 & 0 & 0 & 1 & 0 & 3 & 4 & 1 & 0 \\
\hline 0 & 0 & 1 & & 1 & 0 & 4 & 3 & 2 & 1 & 1 & 0 \\
\hline 0 & 1 & & & 1 & 2 & 0 & 2 & 2 & 2 & 1 & 1 \\
\hline 2 & 1 & & & 3 & 3 & 0 & 1 & 3 & 3 & 0 & 0 \\
\hline 2 & 1 & & & 2 & 2 & 1 & 1 & 0 & & 1 & 0 \\
\hline 3 & 2 & & & 1 & 1 & 2 & 2 & 2 & & 4 & 0 \\
\hline 2 & 1 & & & 2 & 4 & 0 & 0 & 1 & & 1 & 1 \\
\hline 3 & 3 & & & 1 & 5 & 1 & & 0 & & 2 & 2 \\
\hline 1 & 1 & & & 0 & 1 & 1 & & 0 & & & 0 \\
\hline 1 & 0 & & & & 1 & 2 & & & & & 1 \\
\hline 3 & 2 & & & & 1 & 3 & & & & & 0 \\
\hline 2 & & & & & 1 & 1 & & & & & \\
\hline 0 & & & & & 0 & 2 & & & & & \\
\hline 2 & & & & & & & & & & & \\
\hline 1 & & & & & & & & & & & \\
\hline 3 & & & & & & & & & & & \\
\hline 2 & & & & & & & & & & & \\
\hline 3 & & & & & & & & & & & \\
\hline 3 & & & & & & & & & & & \\
\hline 0 & & & & & & & & & & & \\
\hline
\end{tabular}




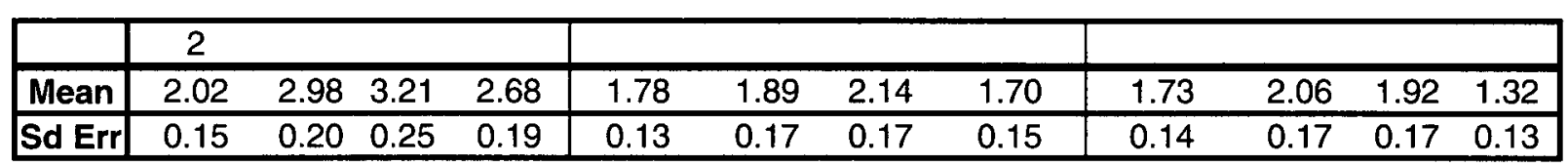




\section{APPENDIX II: STATISTICAL ANALYSES}

NOTE: $n$ is calculated by examining individual cultured rat ventricular myocytes

1) Fractional shortening of myocytes co-incubated with antibodies, after challenge.

No macrophages: ANOVA: $E(2,66)=3.34$, (not significant)

No antibodies: $\quad$ ANOVA: $\underline{E}(2,43)=5.90, p<0.05$

Post hoc (Bonferroni): $\quad$ a) No challenge $>$ TNF $\alpha$ challenge

b) No challenge $>$ LPS challenge

anti-ICAM-1: $\quad$ ANOVA: $\underline{E}(2,37)=0.749$, (not significant)

anti-TNF $\alpha: \quad$ ANOVA: $\underline{F}(2,31)=0.18$, (not significant) 
2) Macrophage adherence to cardiac myocytes:

After 3 hours incubation: ANOVA: $\underline{E}(1,93)=22.59, p<0.001$

After 4 hours incubation: ANOVA: $\underline{F}(1,90)=18.04, p<0.001$

3) Fractional shortening of myocytes co-incubated with oxygen free radical scavengers, NO synthase inhibitors and peroxynitrite inhibitors.

After comparing challenged cells with various additives:

ANOVA: $E(4,92)=3.82, p<0.005$

Post hoc (Bonferroni): $\quad$ a) challenged $<\mathrm{SOD}$

b) challenged $<$ L-NAME

c) challenged $<$ desferoxamine 
4) Mean macrophage adherences after co-incubation with oxygen free radical scavengers, peroxynitrite inhibitors, NO synthase inhibitors.

After comparing challenged cells vs unchallenged cells:
a) no additives: $\quad$ ANOVA: $\underline{F}(1,44)=3.15$, (not significant)
b) desferoxamine: ANOVA: $\underline{F}(1,40)=3.21$, (not significant)
c) SOD:
ANOVA: $E(1,44)=0.13$, (not significant)
d) L-NAME:
ANOVA: $\underline{F}(1,43)=2.57$, (not significant)
e) urate:
ANOVA: $E(1,43)=0.20$, (not significant)

5) Relationship between adherent macrophages and fractional shortening.

ANOVA: $\underline{F}(4,119)=1.65, p=0.07$

Fractional shortening:

a) 2 adherent macrophages $>6$ macrophages

b) 4 adherent macrophages $>6$ macrophages 
6) Diastolic lengths of cardiac myocytes.

ANOVA: $\underline{F}(1,39)=3.83$, (not significant)

7) Myocytes incubated with macrophages after addition of well inserts.

ANOVA for co-incubated cells vs inserts:
a) no challenge: $\quad \underline{F}(1,20)=2.36$, (not significant)
b) $\underline{\text { TNF } \alpha \text { challenge: }} \underline{\mathrm{F}}(1,30)=4.01, p<0.05$
c) LPS challenge: $\quad E(1,32)=5.01, p<0.05$ 
8) Mean macrophage adherences after co-incubation with antibodies and challenge.

a) No antibodies: ANOVA: $E(3,347)=7.21, p<0.001$

Post hoc (Bonferroni):
a) No challenge $>$ TNF $\alpha$ challenge
b) No challenge > LPS challenge
c) No challenge $>$ IL-1 $\beta$ challenge

b) Anti-ICAM-1: $\quad$ ANOVA: $\underline{F}(3,354)=1.51$, (not significant)

c) Anti-TNF $\alpha$ : ANOVA: $\underline{F}(3,344)=4.50$, (not significant) 